\title{
ecgi
}

\section{Network-Sensitive Financial Regulation}

Law Working Paper N 451/2019

May 2019

\section{Luca Enriques}

University of Oxford and ECGI

Alessandro Romano

Yale University

Thom Wetzer

University of Oxford

(C) Luca Enriques, Alessandro Romano and Thom Wetzer 2019. All rights reserved. Short sections of text, not to exceed two paragraphs, may be quoted without explicit permission provided that full credit, including (C) notice, is given to the source.

This paper can be downloaded without charge from: http://ssrn.com/abstract_id=3387708

www.ecgi.global/content/working-papers 


\title{
Network-Sensitive Financial Regulation
}

\author{
Working Paper N 451/2019 \\ May 2019 \\ Luca Enriques \\ Alessandro Romano \\ Thom Wetzer
}

We wish to thank John Armour, Dan Awrey, Guido Calabresi, Horst Eidenmüller, Doyne Farmer, Stavros Gadinis, Henry Hansmann, Jesse Kaijser, Yair Listokin, Pedro Machado, Katrien Morbee, John Morley, Alan Morrison, Roberta Romano, Alan Schwartz, Christina Parajon Skinner, Oren Sussman, and participants to an Oxford Business Law Workshop, the 3d European Banking Institute Global Annual Conference on Banking Regulation (Frankfurt am Main), for helpful comments and suggestions. Usual disclaimers apply.

(C) Luca Enriques, Alessandro Romano and Thom Wetzer 2019. All rights reserved. Short sections of text, not to exceed two paragraphs, may be quoted without explicit permission provided that full credit, including $(\mathbb{C}$ notice, is given to the source. 


\begin{abstract}
Shocks that hit part of the financial system, such as the subprime mortgage market in 2007, can propagate through a complex network of interconnections among financial and non-financial institutions. As the financial crisis of 20072009 has showed, the consequences for the entire economy of such systemic risk materializing can be catastrophic. Following the crisis, economists and policymakers have become increasingly aware that the structure of the financial system is a key determinant of systemic risk. A wide consensus now exists among them that network theory is the natural framework for studying systemic risk. Yet, most of the existing rules in financial regulation are still "atomistic," in that they fail to incorporate the fact that each individual institution is part of a wider network. This article shows that policies building upon insights from network theory (networksensitive policies) can address systemic risk more effectively than traditional atomistic policies also in areas where an atomistic approach would seem natural, such as the corporate governance of systemically important financial institutions. In particular, we consider four prescriptions for the governance of systemically important institutions (one on directors' liability, two on executive compensation and one on failing financial institutions' shareholders appraisal rights in mergers) and show how making them network-sensitive would both increase their effectiveness in taming systemic risk and better calibrate their impact on individual institutions.
\end{abstract}

Keywords: Bank Governance, Corporate Governance, Macroprudential Supervision, Network Theory, Systemically Important Financial Institutions (SIFIs), Systemic Risk.

JEL Classifications: G18, G28, K22, K29

\title{
Luca Enriques*
}

Allen \& Overy Professor of Corporate Law

University of Oxford, Faculty of Law

St.Cross Building, St. Cross Road

Oxford, OX1 3UL, United Kingdom

phone: +44 1865279751

e-mail: luca.enriques@law.ox.ac.uk

\section{Alessandro Romano}

Researcher

Yale University, Yale Law School

127 Wall St

New Haven, CT 06511, United States

e-mail: alessandro.romano@yale.edu

\section{Thom Wetzer}

Researcher

University of Oxford, Faculty of Law

St. Cross Building, St. Cross Road

Oxford OX1 3UL, United Kingdom

e-mail: thom.wetzer@law.ox.ac.uk 


\title{
NETWORK-SENSITIVE FINANCIAL REGULATION
}

\author{
Luca Enriques \\ Alessandro Romano \\ Thom Wetzer (*)
}

Forthcoming in The Journal of Corporation Law

May 2019

Shocks that hit part of the financial system, such as the subprime mortgage market in 2007, can propagate through a complex network of interconnections among financial and non-financial institutions. As the financial crisis of 2007-2009 has showed, the consequences for the entire economy of such systemic risk materializing can be catastrophic. Following the crisis, economists and policymakers have become increasingly aware that the structure of the financial system is a key determinant of systemic risk. A wide consensus now exists among them that network theory is the natural framework for studying systemic risk. Yet, most of the existing rules in financial regulation are still "atomistic," in that they fail to incorporate the fact that each individual institution is part of a wider network.

This article shows that policies building upon insights from network theory (network-sensitive policies) can address systemic risk more effectively than traditional atomistic policies also in areas where an atomistic approach would seem natural, such as the corporate governance of systemically important financial institutions. In particular, we consider four prescriptions for the governance of systemically important institutions (one on directors' liability, two on executive compensation and one on failing financial institutions' shareholders appraisal rights in mergers) and show how making them network-sensitive would both increase their effectiveness in taming systemic risk and better calibrate their impact on individual institutions.

Keywords: Bank Governance, Corporate Governance, Macroprudential Supervision, Network Theory, Systemically Important Financial Institutions (SIFIs), Systemic Risk.

JEL Classifications: G18, G28, K22, K29

(*) University of Oxford and ECGI, Yale Law School, and University of Oxford, respectively. We wish to thank John Armour, Dan Awrey, Guido Calabresi, Horst Eidenmüller, Doyne Farmer, Stavros Gadinis, Henry Hansmann, Jesse Kaijser, Yair Listokin, Pedro Machado, Katrien Morbee, John Morley, Alan Morrison, Roberta Romano, Alan Schwartz, Christina Parajon Skinner, Oren Sussman, and participants to an Oxford Business Law Workshop, the 3d European Banking Institute Global Annual Conference on Banking Regulation (Frankfurt am Main), for helpful comments and suggestions. Usual disclaimers apply. 


\section{CONTENTS}

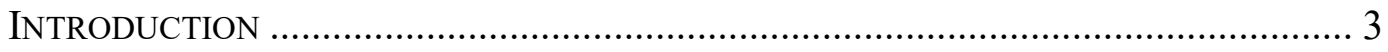

I. The Microprudential APPROACH to FinANCIAL REgULATION ................... 8

A. Pre-Crisis Convention: Atomistic Microprudential Regulation ................ 8

B. Post-Crisis Criticisms of Atomistic Microprudential Regulation ............... 9

II. AtOMISTIC AND NETWORK-SENSITIVE MACROPRUDENTIAL FINANCIAL

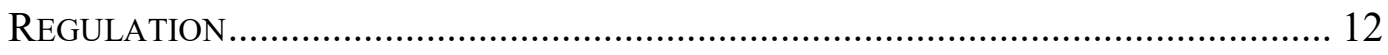

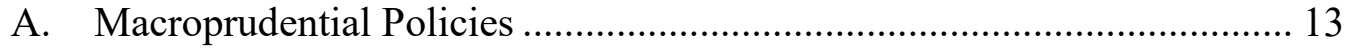

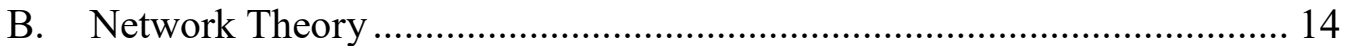

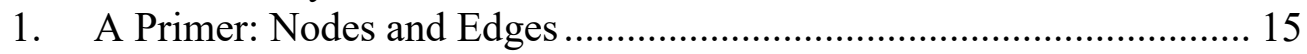

2. Centrality.................................................................................. 15

3. Resilience to Shocks: Density...................................................... 18

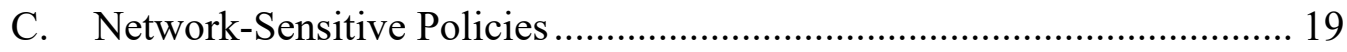

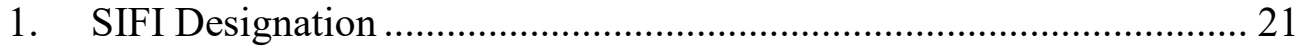

2. The Risk-Based Capital Surcharge .................................................. 23

3. Stress Tests....................................................................................... 24

4. Optimal Network Topology Design Policies ........................................ 26

D. Conclusion: A Stylized Taxonomy of Prudential Regulation.................. 27

III. NETWORK-SENSITIVE SIFI GOVERnANCE REQUIREMENTS: How IT WOULD WORK 29

A. Corporate vs SIFI Governance......................................................... 29

B. Personal Liability of Directors and Managers ..................................... 32

C. Managerial Compensation .............................................................. 40

D. Failing SIFI Shareholder Rights in Shadow Resolutions ....................... 43

E. Bumpy Atomistic Rules Versus Smooth Network-Sensitive Ones ......... 46

IV. Possible Counterarguments to Network-SENSITIVE REgUlations 47

V. Research Agenda: The CASE Of Disclosure ANd RePorting

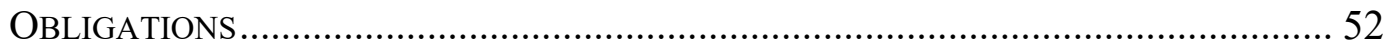

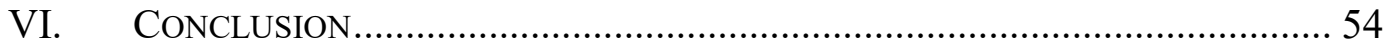




\section{"Network analysis [...] has the potential to help us better monitor the interconnectedness of financial institutions and markets." \\ Ben Bernanke ${ }^{1}$}

\section{INTRODUCTION}

In the wake of the 2007-09 financial crisis, economists and policymakers alike have become increasingly aware that the structure of the financial system is a key determinant of systemic risk. ${ }^{2}$ Shocks that hit part of the system, such as the subprime mortgage market in 2007, can propagate through a complex network of interconnections among financial and non-financial institutions and, ultimately, have a catastrophic impact on the entire economy. ${ }^{3}$ In the absence of this network, localized shocks hitting individual players or specific parts of a financial system would not propagate. To put it differently, systemic risk naturally presupposes the existence of a system, which consists of a network of interconnected actors. The

\footnotetext{
${ }^{1}$ Ben Bernanke, Chairman, Bd. of Governors of the Fed. Reserve Sys., Monitoring the Financial System, Speech at the 49th Annual Conference on Bank Structure and Competition sponsored by the Federal Reserve Bank of Chicago (May 10, 2013), available at https://www.federalreserve.gov/newsevents/speech/bernanke20130510a.htm.

${ }^{2}$ See e.g. Daron Acemoglu, Asuman Ozdaglar \& Alireza Tahbaz-Salehi, Systemic Risk and Stability in Financial Networks, 105 AM. ECON. REV. 564, 564 (2015) ("Since the global financial crisis of 2008 , the view that the architecture of the financial system plays a central role in shaping systemic risk has become conventional wisdom").

${ }^{3}$ Ryan Bubb \& Prasad Krishnamurthy, Regulating Against Bubbles: How Mortgage Regulation Can Keep Main Street And Wall Street Safe-From Themselves, 163 U. PA. L. REV. 1539, 1542 (2014) (describing how the shock hitting the real estate market had dramatic consequences on the U.S. economy); Steven L. Schwarcz, Derivatives and Collateral: Balancing Remedies and Systemic Risk, 2015 U. ILL. L. REV. 699, 700 (2015) (defining systemic risk as "the risk that an event will trigger a loss of economic value or confidence in a substantial segment of the financial system that is serious enough to have significant adverse effects on the real economy"); John C. Coates IV, Cost-Benefit Analysis of Financial Regulation: Case Studies and Implications, 124 YALE L.J. 882, 894 (2014) (noting that "financial markets are tightly interconnected systems (hence the now mainstream phrase "systemic risk"), in which one party's losses can be rapidly transmitted to multiple related parties"). See also Sheri Markose, Simone Giansante \& Ali Rais Shaghaghi, 'Too Interconnected to Fail' Financial Network of US CDS market: Topological fragility and systemic risk, 83 J. ECON. BEHAVIOR \& ORG. 627, 627 (2012) (noting that "[t]he 2007 financial crisis which started as the US 'sub-prime' crisis, through a process of financial contagion led to the demise of major banks and also precipitated severe economic contraction the world over"). For an overview of the literature, see also Christoph Aymanns, J. Doyne Farmer, Alissa M. Kleinnijenhuis \& Thom Wetzer, Models of Financial Stability and Their Application in Stress Tests, in 4 HANDBOOK OF COMPUTATIONAL ECONOMICs 329 passim (Cars Hommes \& Blake LeBaron eds., 2018).
} 
resulting "[c]omplex links among financial market participants and institutions are a hallmark of the modern global financial system."4

Given the importance of networks to understand the financial system and the systemic risk it generates, the use of network theory to inform financial regulatory policy would seem a natural approach. ${ }^{5}$ Yet, while leading researchers from many disciplines identify network theory as the natural framework for studying systemic risk, ${ }^{6}$ legal scholars have largely overlooked this perspective. ${ }^{7}$ More importantly, policymakers' use of network theory insights to curb systemic risk has been patchy so far, ${ }^{8}$ despite the fact that, following the financial crisis, they have refocused their attention from regulations attempting to preserve the stability of individual banks ("microprudential" regulations or policies) to policies aimed at ensuring the stability of the system as a whole ("macroprudential" regulations or policies). ${ }^{9}$

Our key argument is that the transition to a regulatory regime that can effectively mitigate systemic risk in the modern hyper-connected economy will not be complete until financial regulation fully accounts for the structure of the financial network and the interconnections among its components. That is true also

${ }^{4}$ Janet L. Yellen, Vice Chair, Bd. of Governors of the Fed. Reserve Sys., Interconnectedness and Systemic Risk: Lessons from the Financial Crisis and Policy Implications, Speech at the American Economic Association / American Finance Association Joint Luncheon, San Diego, California (Jan. 4, 2013), available at https://www.federalreserve.gov/newsevents/speech/yellen20130104a.htm.

${ }_{5}^{5}$ See e.g. Andrew G Haldane \& Robert M. May, Systemic Risk in Banking Ecosystems, 469 NATURE 351 (2011) (advocating the use of network theory to craft regulations aimed at taming systemic risk). ${ }^{6}$ Besides leading economists like the Nobel Laureate Joseph E. Stiglitz (Tarik Roukny, Stefano Battiston \& Joseph E. Stiglitz, Interconnectedness as Source of Uncertainty in Systemic Risk, 35 J. FIN. STABILITY 93 (2016)) and Daron Acemoglu (Acemoglu et al. supra note 2), a leading physicist (Albert-László Barabási, The Network Takeover, 8 NATURE PHYSICS 14 (2011)) and, jointly, zoologists, biologists and ecologists (Robert M. May, Simon A. Levin \& George Sugihara, Complex Systems: Ecology for Bankers, 451 NATURE 893 (2008)) have analyzed financial systems through the lens of network theory.

${ }^{7}$ Legal scholars have largely overlooked network theory, despite the fact that patterns of interactions among individuals and institutions are a crucial determinant of the effects of legal norms. The few exceptions include Alan Schwartz \& Robert E. Scott, Third-Party Beneficiaries and Contractual Networks, 7 J. LEG. ANALYSIS 325 (2015) (applying network theory to analyze the functioning of contractual networks); CRISTIE FORD, INNOVATION AND THE STATE 202-06 (2018) (referring to network analysis as a useful tool to understand the dynamics of diffusion of financial innovation); Luca Enriques \& Alessandro Romano, Institutional Investor Voting Behavior: A Network Theory Perspective, 2019 U. ILL. L. REV. (forthcoming) (studying the voting behavior of institutional investors); Laura G. Pedraza-Farina \& Ryan Whalen, A Network Theory of Patentability 87 U. CHI. L. REV (forthcoming) (using network theory to develop a new conceptual definition of 'nonobviousness' in patent law); Alessandro Romano, Horizontal Shareholding: The End of Markets and the Rise of Networks (2018), available at https://papers.ssrn.com/sol3/papers.cfm?abstract_id=3255948 (using network theory to frame the antitrust policy implications of common ownership).

${ }^{8}$ See infra, Section II.D.

${ }^{9}$ See infra Part I and II. 
for policies designed to improve the corporate governance of what have come to be known as systemically important financial institutions (hereinafter, "SIFIs"), the financial intermediaries that are so designated by regulators in light of their ability to destabilize the financial system in case of failure. ${ }^{10}$

The goal of this article is to show that network theory can also be of great help in the corporate governance domain. ${ }^{11}$ There is a fundamental reason to pay attention to SIFI corporate governance, and thus to reshape the policies affecting it by incorporating insights from network theory (hereinafter, "network-sensitive policies" or "network-sensitive regulations"). Instead of imposing a straitjacket on SIFIs via limits on SIFIs balance sheets and activities, which is bound to be illfitting given SIFIs' extreme complexity, corporate governance rules aim at improving the incentives of the economic agents at their helm. The idea is that most of the regulation implemented thus far, such as capital requirements, identify a specific behavior that SIFIs should adopt, whereas the rules discussed in this article aim at providing the actors that influence SIFIs' behavior, such as managers and directors, with the right incentives, so that they determine the best course of action.

To show how insights from network theory can make SIFI governance regulations more effective in taming systemic risk, we consider four policy prescriptions, three of which have been put forth by legal scholars, and one that has become law within the European Union (hereinafter, the "E.U."). To be clear, we remain agnostic on whether these reforms are in principle desirable. Our purpose is not to argue in favor of (or against) any specific proposal but rather to highlight the advantages of a shift of paradigm in the direction of network-sensitive regulation in the area of corporate governance.

We first discuss the idea, advocated by John Armour and Jeffrey Gordon, of imposing personal liability on managers and directors of SIFIs. ${ }^{12}$ Armour and Gordon argue that managers and directors of SIFIs lack the incentives to account for the systemic relevance of their firm when they decide on a course of action. On the one hand, the compensation of managers and officers is generally tied to the performance of their firms. On the other, U.S. corporate governance pushes managers to focus on stock price maximization. ${ }^{13}$ As a result, managers of SIFIs have every incentive to maximize shareholder value, even when so doing creates significant systemic risk. ${ }^{14}$ Armour and Gordon claim that personal liability is an

\footnotetext{
${ }^{10}$ See infra, Section II.D.1.

${ }^{11}$ Note that the essence of this article's analysis holds for the regulation of actions that more generally create externalities, provided that the intensity and diffusion of these externalities depend on the structure of the underlying network. In this article, however, we have chosen to focus on systemic risk in financial systems because of its unique salience as a trigger of financial and economic meltdown.

${ }^{12}$ John Armour \& Jeffrey N. Gordon, Systemic Harms and Shareholder Value, 6 J. LEG. ANALYSIS 35 (2014).

${ }^{13}$ Id. at $37-39$.

${ }^{14} \mathrm{Id}$.
} 
effective means to counter these perverse incentives, because it would induce managers and directors to internalize the systemic relevance of their firm. We show that their proposal may better achieve this goal if amended to incorporate the insights of network theory. In fact, accounting for a SIFI's interconnectedness, via available measures of their "centrality" in the network, ${ }^{15}$ better ensures that managers and directors of firms that can impose higher losses on the economy face higher expected liability. ${ }^{16}$

Second, some scholars have argued that the compensation structure for managers of systemically important firms - and in particular banks - should be regulated. ${ }^{17}$ The basic idea here is that, if bank managers are compensated predominantly with stock and stock options, they will share all the potential gains from successful investments, but will be insulated from part or all of the potential losses in the event of negative outcomes. ${ }^{18}$ As a consequence, bank managers will take excessive risks and impose negative externalities on the economy as a whole. ${ }^{19}$ For this reason, Bebchuk and Spamann have suggested that part of bank managers' compensation should be based on a broader basket of securities that includes preferred stocks and bonds, inducing managers to internalize a larger fraction of potential losses from risky projects. ${ }^{20}$ Similarly, but more radically, post-crisis European banking regulations have set a cap on variable compensation equal to 100 percent of the fixed compensation elements (200 percent with shareholder approval). ${ }^{21}$

Without a network-sensitive component, however, these policies are not sufficiently flexible to accommodate the specific characteristics of the various SIFIs and, therefore, would place excessively stringent constraints on some SIFIs and be too lax on others. Instead, we show how network theory would allow policymakers to tailor the structure of managers' compensation to the specific features of the various SIFIs. Managers of SIFIs that create more systemic risk will receive, other things equal, less shares and more bonds than managers of SIFIs that pose a relatively smaller threat to the stability of the system.

\footnotetext{
${ }^{15}$ See infra Section II.B.2.

${ }^{16}$ See infra Section III.B.

${ }^{17}$ See e.g. Lucian A. Bebchuk \& Holger Spamann, Regulating Bankers' Pay, 98 GeO. L.J. 247 (2009); Sanjai Bhagat \& Roberta Romano, Reforming Executive compensation: Focusing and Committing to the Long-Term, 26 YALE J. ON REG. 359 (2009); Frederick Tung, Pay for Banker Performance: Structuring Executive Compensation for Risk Regulation, 105 NW. U. L. REV. 1205 (2011); Sanjai Bhagat, Brian Bolton \& Roberta Romano, Getting Incentives Right: Is Deferred Bank Executive Compensation Sufficient, 31 YALE J. ON REG. 523 (2014).

${ }^{18}$ Bebchuk \& Spamann, supra note 17, at 247 (noting that bank executives "are insulated from losses that the realization of risks could impose on preferred shareholders, bondholders, depositors, and taxpayers").

${ }^{19} I d$. at 249 .

${ }^{20} I d$. at 253.

${ }^{21}$ See infra notes 178-179 and accompanying text.
} 
Finally, we discuss a proposal by Yair Listokin and Inho Mun. They contend that "regulation by deal," in which a solid firm acquires a defaulting SIFI, is an important tool for mitigating systemic risk.22 Yet, as they show, regulation by deal is problematic because it allows the shareholders of the defaulting SIFI to hold the economy hostage: ${ }^{23}$ shareholders are aware that by opposing the merger deal they can impose a significant externality on society, which allows them to extract rents from the buyer's shareholders and/or taxpayers. ${ }^{24}$ For this reason, Listokin and Mun suggest that merger voting rights attaching to the target SIFI shares should be replaced by appraisal rights. ${ }^{25}$ This proposal entails a trade-off. Because appraisal rights are very favorable to shareholders, ${ }^{26}$ managers might be induced to act in a reckless way and shareholders might refrain from monitoring them, given that shareholders will be made whole even if the firm goes bankrupt. ${ }^{27}$ That is why Listokin and Mun argue that shareholders should be awarded only a fraction of the appraisal value. At the same time, however, insufficiently compensating shareholders for their voting rights would amount to expropriation and would create problems in capital allocation. More specifically, if investors know that they can be stripped of their voting rights without receiving adequate compensation, it will be harder for a SIFI to raise capital, especially if it is close to insolvency but still viable. As we show in Section III.C, it is easier to address this trade-off if one builds upon the insights from network theory. To summarize, we show that network tools can be used to improve traditional atomistic policy prescriptions designed to mitigate systemic risk, even in an area - corporate governance - where such ideas have so far not been deployed.

The Article proceeds as follows. Part I describes the traditional microprudential approach to financial regulation and its shortcomings. Part II describes the rise of macroprudential regulation and introduces the concept of network-sensitive regulations. Part III develops the core argument by showing how network theory can make SIFI governance prescriptions more effective in curtailing systemic risk. Part IV addresses some potential counterarguments to the use of network theory in that domain. Part $\mathrm{V}$ briefly discusses the implications for disclosure and reporting requirements of a network approach to financial regulation. Part VI concludes.

\footnotetext{
${ }^{22}$ Yair Listokin \& Inho A. Mun, Rethinking Corporate Law During a Financial Crisis, 8 HARV. BUS. L. REV. (forthcoming) (manuscript at 4), available at https://papers.ssrn.com/sol3/papers.cfm?abstract_id=3105175.

23 Id. at 16 .

${ }^{24} I d$.

${ }^{25}$ Id. at 27-30.

${ }^{26}$ See e.g. Matthew D. Cain, Jill Fisch, Steven Davidoff Solomon \& Randall S. Thomas, The Shifting Tides of Merger Litigation, 71 VAND. L. REV. 603, 612 (2018) (briefly describing Delaware's appraisal remedy and the features that make it generous from the shareholders' perspective).

${ }^{27}$ Listokin \& Mun, supra note 22, at 29.
} 


\section{The MicRoprUdential APPROACH TO FINANCIAL REGULATION}

Prior to the financial crisis of 2007-09, the core policy tools to preserve financial stability focused on safeguarding the resilience of individual financial institutions. ${ }^{28}$ However, the dynamics triggered by the crisis exposed the serious limitations of that model of financial regulation. This part briefly describes the atomistic nature of the pre-crisis model and summarizes its flaws as an introduction to the new tools for financial regulation that have taken center stage in the aftermath of the crisis.

\section{A. Pre-Crisis Convention: Atomistic Microprudential Regulation}

Before the crisis, prudential regulation was largely microprudential and atomistic in nature: it was designed to counter bankruptcy risk at the individual firm level, ${ }^{29}$ and implicitly treated financial institutions as if they existed in isolation.

The posterchild of this approach were the capital buffers that banks were required to maintain as protection against financial shocks: they were calibrated to the risks held on the balance sheet of each individual bank, giving little weight, if any, to how interconnections among financial institutions affected individual firms' riskiness. ${ }^{30}$ Clearly, policymakers' reliance on atomistic microprudential regulation did not mean that their ultimate concern was not the resilience of the financial system as a whole. ${ }^{31}$ But the underlying assumption was that, if regulators ensured the resilience of individual financial institutions, the stability of the financial system would follow. ${ }^{32}$ This assumption, by and large, rested upon the idea that financial contagion operates like falling dominos: firms pass on the shock if they topple, but as long as individual firms are resilient enough to withstand incoming shocks the dominos remain standing and the system is secure. ${ }^{33}$

28 John ARMOUR ET AL., PrinCIPLES OF FinANCIAL REgUlation 409, 416-17 (2016).

${ }^{29}$ Daniel K. Tarullo, Macroprudential Regulation 31 YALE J. ON REG. 505, 507-08 (2014).

${ }^{30}$ See generally MiCHAEL S. BARR, HOWELl E. JACKSON \& MARGARET E. TAHYAR, FINANCIAL REGULATION: LAW AND POLICY 310 (2d ed. 2018) (singling out lack of concern about the financial system's interconnectedness as one of the main shortcomings of pre-financial crisis capital requirements).

${ }^{31}$ See Tarullo, supra note 29, at 507 (clarifying that systemic risk concerns were at the core of banking regulation since the 1930s).

32 ARMOUR ET AL., supra note 28, at 416 ("Regulators' mistake prior to the crisis was not to assume that microprudential measures were necessary for ensuring financial stability - they surely are - but rather to assume that pre-crisis microprudential measures were, by themselves, sufficient to do so").

${ }^{33}$ Franklin Allen \& Douglas Gale, Financial Contagion, 108 J. POL. ECON. 1 passim (2000) (modeling systemic risk as arising from liquidity shocks - passed on via interbank deposits - that can have a domino effect). 


\section{B. Post-Crisis Criticisms of Atomistic Microprudential Regulation}

The 2007-09 financial crisis exposed the atomistic microprudential view as misguided and incomplete. ${ }^{34}$ First, banks' main response to incoming shocks was to strengthen their own position by selling assets and hoarding capital. ${ }^{35}$ From the perspective of an individual bank, this may seem a prudent response and, moreover, one consistent with the prescriptions of atomistic microprudential financial regulation. If banks collectively take such actions, however, asset prices will collapse and interbank lending markets will dry up. ${ }^{36}$ This, in turn, puts further strain on banks, so that they have to take additional steps to strengthen their financial position. As this feedback loop gets underway, it worsens the already adverse economic conditions by encouraging herding behavior. ${ }^{37}$ Even though the actions that firms take in these feedback loops may be rational individually, they are damaging collectively: in a classic fallacy of composition, rules promoting behavior that is appropriate at the level of the single bank increase the fragility of the system as a whole. ${ }^{38}$

${ }^{34}$ See e.g. Lael Brainard, Governor, Bd. of Governors of the Fed. Reserve Sys., Dodd-Frank at Five: Assessing Progress on Too Big to Fail, Speech at the "Dodd-Frank at Five: Looking Back and Looking Forward" event, Bipartisan Policy Center and Managed Funds Association, Washington D.C. (July 9, 2015), available at https://www.federalreserve.gov/newsevents/speech/brainard20150709a.htm_("The limits of the microprudential approach were particularly evident with respect to very large, interconnected firms").

35 See e.g. Viral V. Acharya \& Ouarda Merrouche, Precautionary Hoarding of Liquidity and Interbank Markets: Evidence from the Subprime Crisis 17 REV. FIN. 1, 107-160 (2012) (showing that banks, following a freeze in money markets on 9 August 2007, engaged in precautionary hoarding of liquidity and continued to do so through the ensuing crisis).

${ }^{36}$ See e.g. Gary B. Gorton \& Andrew Metrick, Securitized Banking and the Run on Repo 104 J. FIN. ECON. 3, 425 passim (2012) (discussing the destabilizing effect of margin and the 'run on repo' in securitized banking activities).

${ }^{37}$ See e.g. Viral V. Acharya \& Tanju Yorulmazer, Information Contagion and Bank Herding, $40 \mathrm{~J}$. MONEY, CREDIT \& BANKING 215 passim (2008) (showing that information contagion can lead to herding behaviour).

${ }^{38}$ In their influential paper, Adrian and Shin document that behavior induced by marked-to-market leverage is strongly procyclical: see Tobias Adrian \& Hyun S. Shin, Liquidity and Leverage, 19 J. FIN. INTERMEDIATION 418 passim (2010). See also Robin Greenwood, Augustin Landier \& David Thesmar, Vulnerable Banks 115 J. FIN. ECON. 3, 471, 473 (2015) (noting that, when banks are hit by a shock, they sell assets to return to their leverage target to ensure their resilience and meet their regulatory requirements and how this may trigger contagion); Rama Cont \& Eric Schaanning, Fire Sales, Indirect Contagion and Systemic Stress Testing, Norges Bank Working Paper passim (2017), https://www.norges-bank.no/en/Published/Papers/Working-Papers/2017/22017/ (showing that asset losses triggered by macro-shocks may interact with one-sided portfolio constraints, such as leverage or capital constraints, resulting in the liquidation of assets, which in turn affects market prices, leading to contagion of losses and possibly new rounds of fire sales when portfolios are marked to market); Christoph Aymanns \& J. Doyne Farmer, The Dynamics of the Leverage Cycle 
A second shortcoming of atomistic microprudential financial regulation is that it implicitly assumes that the risk posed by each institution to the financial system is a function of the atomistic characteristics of that firm (predominantly, its asset size). ${ }^{39}$ However, it became clear during the crisis that some financial institutions, by virtue not only of their size but also of their interconnectedness or lack of substitutability, pose more severe risks to the system than others. ${ }^{40}$ Accordingly, their failure would have vastly more severe consequences on the financial system as a whole than their atomistic characteristics alone would suggest, to the point that the risks resulting from such failure would be "systemic." 41 Financial institutions that possess such characteristics are referred to as SIFIs. Although their existence was acknowledged before the 2007-2009 financial crisis, mostly under the "too-big-to-fail" label, ${ }^{42}$ this insight had not been reflected in the regulatory framework. Looking back on the factors that caused the financial crisis, it is clear that regulators were not necessarily aware of the extent to which

50 J. ECON. DYNAMICS \& CONTROL 155 passim (2015) (showing that a value-at-risk constraint can lead to procyclical leverage, or 'leverage cycles'); Christoph Aymanns, Fabio Caccioli, J. Doyne Farmer \& Vincent W.C. Tan, Taming the Basel Leverage Cycle 27 J. FIN. STABILITY 263 passim (2016) (showing how value-at-risk constraints mandated by Basel II can endogenously create instability by causing asset price bubbles); Robert Hockett, Are Bank Fiduciaries Special?, 68 ALA. L. REV. 1071, 1074, 1076-79 (2017) (arguing that in financial markets iterative, self-exacerbating collective action problems are pervasive and explain systemic financial crises).

${ }^{39}$ With specific regard to capital requirements, see Daniel K. Tarullo, Governor, Bd. of Governors of the Fed. Reserve Sys., The Evolution of Capital Regulation, Speech at the Clearing House Business Meeting and Conference, New York, New York (Nov. 9, 2011), available at https://www.federalreserve.gov/newsevents/speech/tarullo20111109a.htm

[T] he crisis validated the concerns expressed by some academics and by policy staff at the Bank for International Settlements that the effectiveness of capital regulation was limited by its exclusively microprudential focus. Capital requirements had been set with reference solely to the balance sheet of a specific firm. (...) The limits of the microprudential approach were particularly evident with respect to very large, interconnected firms.

${ }^{40}$ As then Vice-Chair of the Federal Reserve Janet Yellen put it:

The emergence of [risky] behavior among the largest and most interconnected financial institutions is particularly dangerous, since these institutions are linchpins in our financial system, and their failure could cause significant damage to large numbers of counterparties and the system as a whole, as the examples of Lehman Brothers and American International Group demonstrate.

Janet L. Yellen, Vice Chair, Bd. of Governors of the Fed. Reserve Sys., Macroprudential Supervision and Monetary Policy in the Post-Crisis World, Speech at the Annual Meeting of the National Association for Business Economics, Denver, Colorado (Oct. 11, 2010), available at https://www.federalreserve.gov/newsevents/speech/yellen20101011a.htm.

${ }^{41}$ See Alan D. Morrison, Systemic Risk and the "Too-Big-to-Fail" Problem, 27 OXFORD REV. ECON. POL'Y 3 (2011).

${ }^{42}$ On the notion of 'too-big-to-fail', see e.g. GARY H. STERn \& RON J. FELDMAN, TOO BIG TO FAIL: THE HAZARDS OF BANK BAILOUTS (2009). 
networked risks introduced fragility for which atomistic regulation failed to account.

As the crisis unfolded, regulators were confronted by the risks posed by procyclical interactions between interconnected SIFIs, ${ }^{43}$ and the shortcomings of the atomistic microprudential perspective became painfully clear. As then Federal Reserve Chairman Ben Bernanke remarked:

"[A] key lesson of the crisis is that a purely microprudential approach, focused on the conditions of individual firms or markets, may fail to detect important systemic or cross-cutting risks. For example, a traditional microprudential examination might find that an individual financial institution is relying heavily on short-term wholesale funding, which may or may not induce a supervisory response. The implications of that finding for the stability of the broader system, however, cannot be determined without knowing what is happening outside that particular firm. Are other, similar financial firms also highly reliant on short-term funding? If so, are the sources of short-term funding heavily concentrated? Is the market for short-term funding likely to be stable in a period of high uncertainty, or is it vulnerable to runs? If short-term funding were suddenly to become unavailable, how would the borrowing firms react--for example, would they be forced into a fire sale of assets, which itself could be destabilizing, or would they cease to provide funding or critical services for other financial actors?"44

The networked and system-wide nature of the crisis events was clear: procyclical feedback loops exacerbated by microprudential regulation operated over the interlinkages between financial institutions, amplifying the initial shock and spreading it throughout the financial system. ${ }^{45}$ Individual firms that were tightly connected to many other financial institutions had an especially pronounced capacity to endanger the financial system, given that their failure could cause them to act as conduits spreading distress to many other firms. ${ }^{46}$ Bear Stearns, a relatively

\footnotetext{
${ }^{43}$ For an account, see e.g. HAL S. SCOTT, ConNECTEDNESS AND CONTAGION: FinANCIAL PANiCS AND THE CRISIS OF 2008 19-58, 67-78 (2016).

${ }^{44}$ Ben Bernanke, Chairman, Bd. of Governors of the Fed. Reserve Sys., Implementing a Macroprudential Approach to Supervision and Regulation, Speech at the 47th Annual Conference on Bank Structure and Competition (May 5, 2011), available at https://www.federalreserve.gov/newsevents/speech/bernanke20110505a.htm.

${ }^{45}$ International Monetary Fund, Global Financial Stability Report: Responding to the Financial Crisis and Measuring Systemic Risks, Ch. 2, 3 (April 2009). For an overview of the literature, see e.g. Aymanns et al., supra note 3, at 347-357.

${ }^{46}$ See e.g. Stefano Battiston et al., DebtRank: Too Central to Fail? Financial Networks, the Fed and Systemic Risk, SCI. REP. 2, 3-5 (2012) (showing that the default of some banks, due to their central position in the financial network and connection to many other financial institutions, would cause a significantly larger economic loss in the financial network than that of other banks).
} 
small financial institution, was the first to be explicitly dubbed 'too-interconnectedto-fail', and the Federal Reserve elected to rescue it on those grounds. ${ }^{47}$ When, in September 2008, the U.S. Government bailed out highly interconnected financial institutions such as Freddie Mac, Fanny Mae and AIG, and let Lehman Brothers, another strongly interconnected firm, fail, the risks associated with interconnectivity materialized; what some had hitherto regarded as a contained crisis became a systemic event. ${ }^{48}$

\section{ATOMISTIC AND NeTWORK-SENSITIVE MACROPRUDENTIAL FINANCIAL REGULATION}

In response to the shortcomings of atomistic microprudential regulation, one new category of policies emerged as part of the global financial rulebook after the crisis: regulators introduced macroprudential policies. In the words of Yellen, "macroprudential policies differ from purely microprudential approaches in that they are intended to protect the financial system as a whole." 49 Unlike microprudential policies, which have hitherto been atomistic, macroprudential policies can either be atomistic or network-sensitive. In the latter case, they explicitly account for the structure of the financial system and the interconnections among its actors, rather than focusing on individual firms. In Section A, we briefly describe macroprudential policies in general. In Section B, we introduce basic concepts of network theory to help elucidate the concept of network-sensitive

${ }^{47}$ Ben Bernanke advanced this argument to justify the Federal Reserve's rescue of Bear Stearns to the Joint Economic Committee. See The Economic Outlook: Hearing Before the Joint Economic Committee, $110^{\text {th }}$ Congress (2008) (statement of Ben S. Bernanke, Chairman, Bd. of Governors of the Fed. Reserve Sys.):

\footnotetext{
Normally, the market sorts out which companies survive and which fail, and that is as it should be. However, the issues raised here extended well beyond the fate of one company. Our financial system is extremely complex and interconnected, and Bear Stearns participated extensively in a range of critical markets. With financial conditions fragile, the sudden failure of Bear Stearns likely would have led to a chaotic unwinding of positions in those markets and could have severely shaken confidence. The company's failure could also have cast doubt on the financial positions of some of Bear Stearns thousands of counterparties and perhaps of companies with similar businesses. Given the current exceptional pressures on the global economy and the financial system, the damage caused by a default by Bear Stearns would have been severe and extremely difficult to contain. Moreover, the adverse effects would not have been confined to the financial system but would have been felt broadly in the real economy through its effects on asset values and credit availability.
}

${ }^{48}$ See International Monetary Fund, supra note 4545, at 135.

${ }^{49}$ Yellen, supra note 40. 
regulations, that we then introduce in Section C. Finally, Section D provides some examples of proposed and implemented network-sensitive regulations.

\section{A. Macroprudential Policies}

After the crisis, policymakers concluded that microprudential regulation was necessary but not of itself sufficient to deal with systemic risk. ${ }^{50}$ Building on that insight, they worked to complement the microprudential approach to financial regulation with a system-wide perspective. Such macroprudential regulatory policies were designed to tackle risks that affected the system as a whole, rather than individual institutions. ${ }^{51}$

An example of a macroprudential policy is the requirement placed upon mortgage lenders to maintain a certain loan-to-value ratio - the relationship between the value of a house offered as collateral and the loan secured upon it - to prevent excessive credit-fueled growth in real estate from generating destabilizing asset booms. ${ }^{52}$ The idea is that preventing such asset bubbles smoothens the economic cycle, thereby mitigating crises and better preserving financial stability. While the concern giving rise to the requirement is clearly macro, the requirement itself is atomistic, because it applies to individual institutions without any consideration for the structure of the network they are part of or their place within it. A full review of atomistic macroprudential policies - which, when introduced, represented a sea change in prudential regulation ${ }^{53}$ - is beyond the scope of this

\footnotetext{
50 See e.g. ARMOUR ET AL., supra note 28, at 409.

${ }^{51}$ See e.g. Bernanke, supra note 44 ("The systemic orientation of the macroprudential approach may be contrasted with that of the traditional, or 'microprudential', approach to regulation and supervision, which is concerned primarily with the safety and soundness of individual institutions, markets, or infrastructures"); Kristin N. Johnson, Macroprudential Regulation: A Sustainable Approach to Regulating Financial Markets, 2013 U. ILL. L. REV. 881, 887 (2013) (arguing that "Macroprudential regulation addresses many of the weaknesses of prudential policy by focusing on both the endogenous events that impact individual financial institutions and the exogenous events that lead to systemic risk concerns").

52 See e.g. ARMOUR ET AL., supra note 28, at 421.

${ }^{53}$ Daniel K. Tarullo, Governor, Bd. of Governors of the Fed. Reserve Sys., Financial Stability Regulation, Speech at the Distinguished Jurist Lecture, University of Pennsylvania Law School, Philadelphia, Pennsylvania (Oct. 10, 2012), available at https://www.federalreserve.gov/newsevents/speech/tarullo20121010a.htm:
}

Taken as a whole, though, the primary aim of [the Dodd-Frank Act] can fairly be read as a reorientation of financial regulation towards safeguarding "financial stability" through the containment of "systemic risk," phrases that both recur dozens of times throughout the statute. The law, explicitly in many provisions and implicitly in many others, directs the bank regulatory agencies to broaden their focus beyond the soundness of individual banking institutions (...). 
article. ${ }^{54}$ More interesting for our purposes are the macroprudential networksensitive regulations that have been implemented thus far. Before reviewing them, in the next section we briefly sketch some key concepts of network theory.

\section{B. Network Theory}

Network theory is a fundamental departure from the methodological individualism traditionally embraced by law and economics scholars. ${ }^{55}$ Instead of concentrating only on the incentives of the basic unit of analysis (an individual agent or institution), network theory also accounts for patterns of interconnections and their evolution over time. ${ }^{56}$ Network theory is a well-developed and scientifically advanced conceptual framework to analyze contexts in which connections are relevant: it provides a rigorous set of tools to identify, describe, and measure connections. ${ }^{57}$ In doing so, it offers a large variety of well-established theoretical insights and empirical findings to build upon. ${ }^{58}$ Most importantly for our purposes, network theory allows one to account for interconnections among financial actors, which are key determinants of systemic risk. ${ }^{59}$

This section briefly introduces the fundamental concepts of network theory that we build upon, first, to make the case for network-sensitive regulation and then, in Part III, to illustrate how it could improve upon atomistic SIFI governancefocused policies.

\footnotetext{
${ }^{54}$ For an overview see Samuel G. Hanson, Anil K. Kashyap \& Jeremy C. Stein, A Macroprudential Approach to Financial Regulation 25 J. ECON. PERSP. 3 passim (2011) (introducing the concept of macroprudential regulation and providing a number of examples).

55 See Geoffrey Brennan \& Gordon Tullock, An Economic Theory of Military Tactics: Methodological Individualism at War, 3 J. ECON. BEHAVIOR \& ORG. 225, 225 (1982) (arguing that in economics "the ultimate unit of analysis is always the individual; more aggregative analysis must be regarded as only provisionally legitimate"). But see Alessandro Romano, Micro-Meso-Macro Comparative Law: An Essay on the Methodology of Comparative Law, 17 CHI. KENT J. INT. \& COMP. L. 1, 5-7 (2016) (noting that an infinite regress problem affects this methodology).

${ }^{56}$ SANJEEV GOYAL, CONNECTIONS: AN INTRODUCTION TO THE ECONOMICS OF NETWORKS 4-7 (2012).

${ }^{57} \mathrm{Id}$, at 2.

${ }^{58}$ For example, in this Article we build upon the many studies that investigate the concept of network centrality. That is, the idea that some components of the network occupy a special position that gives them a specific influence on the functioning of the system as a whole. See e.g. GoYAL supra note 57, at 16-19.

${ }^{59}$ See supra notes 2-6 and accompanying text.
} 


\section{A Primer: Nodes and Edges}

Core components of a network are its nodes and their connections (also called edges). Taken together, the nodes and the edges make up the network topology (that is, the architecture of the network). In the context of financial networks, the nodes represent banks and other financial intermediaries, whereas the edges denote financial flows, social relationships, and other kinds of interactions. ${ }^{60}$ While the literature on networks is very technical, ${ }^{61}$ for the purpose of this article it is sufficient to introduce two basic concepts: centrality, which is the conceptual basis for measuring the relevance of a node in a network, and density, which describes the interconnectedness of the system.

\section{Centrality}

The literature on networks has attempted to devise measures that capture the relevance of a node within a network. ${ }^{62}$ This line of enquiry is crucial for the development of network-sensitive regulations, because it allows policymakers to identify the financial institutions potentially causing greater systemic harm. For instance, the crudest and most intuitive measures of the importance of a given node within a network are the degree and the standardized degree centrality. ${ }^{63}$ The degree of a node refers to the number of direct connections that it has with other nodes. ${ }^{64}$ Therefore, a node with a high degree is directly connected with many other nodes, whereas a node with a low degree has fewer direct connections. Instead, the standardized degree centrality is equal to the degree of the node divided by the maximum possible degree. ${ }^{65}$

The economic literature went beyond these basic measures and developed a number of indicators that have the specific purpose of measuring the level of systemic risk created by a given financial institution. We briefly describe here two indicators that are widely employed by the literature to give a flavor of how they work and what their main strengths and weaknesses are, namely the DebtRank and the Contagion Index. We emphasize, though, that while we advocate for the use of network-sensitive regulation, for various reasons we do not advocate for the

\footnotetext{
${ }^{60}$ See e.g. Marco Galbiati, Danilo Delpini \& Stefano Battiston, The Power to Control, 9 NATURE PHYSICS 126, 126 (2013).

${ }^{61}$ See Mark E.J. Newman, Networks: An Introduction (2010) (providing a general introduction to network theory).

${ }^{62}$ See Linton C. Freeman, Centrality in Social Networks: Conceptual Clarification, 1 SoC. NETWORKS 215 (1978) (providing an overview of centrality measures).

${ }^{63}$ GOYAL, supra note 57, at 16.

${ }^{64} \mathrm{Id}$. at 12.

${ }^{65} \mathrm{Id}$. at 16 .
} 
adoption of a specific indicator. First, developing reliable indicators might require proprietary information that are accessible only to regulators, and hence they cannot easily be developed and tested by scholars. ${ }^{66}$ Second, different network-sensitive regulations might require different metrics to capture what is relevant in different contexts, but exploring different metrics at that level of granularity is beyond the scope of this article. Third, using a single metric might lead to arbitrage, as firms could learn how to game the indicator, which suggests that regulators should use a suite of metrics to calibrate their network-sensitive regulations. ${ }^{67}$ To ease the illustration of how network-sensitive policies may work, however, we do make use of the indicators we now turn to briefly describe.

The DebtRank indicator provides a measure of the portion of a network's total economic value that can be affected by the default of a given node. ${ }^{68}$ For example, calculating the DebtRank of Lehman Brothers would have been an attempt at predicting the economic loss (in dollars) caused by its default. DebtRank has two relevant advantages for policymakers. First, the output is a monetary value, and therefore it is easy to use for policy purposes. For example, it has been used to show that being "too central to fail" may be just as serious a problem as being "too

${ }^{66}$ Dimitrios Bisias Mark Flood, Andrew W. Lo \& Stavros Valavanis, A survey of systemic risk analytics, 4 ANN. REV. FIN. ECON. 255, 257 (2012) ("We recognize that the most useful measures of systemic risk may be ones that have yet to be tried because they require proprietary data only regulators can obtain"). Increasingly, regulators do allow scholars to gain access to granular regulatory network data, subject to confidentiality agreements. See e.g. Mark Paddrik \& H. Peyton Young, How Safe are Central Counterparties in Derivatives Markets?, OFR Working Paper 17-06 (2017) (analyzing the safety of central counterparties in derivatives markets using confidential data from the Depository Trust \& Clearing Corporation (DTCC), which includes all credit default swap transactions reported to the DTCC in which at least one of the counterparties or the reference entity is a U.S. entity). The publication of the results of such research is generally (and understandably) subject to prior approval by the regulator. In practice, key details of the financial network are often deliberately obscured in the published results as part of the approval process, to avoid that regulatory data becomes publicly available.

${ }^{67}$ To be sure, "metrics arbitrage" is made less likely by the fact that, given the parameters of the indicators (in short, interconnections), gaming them would mean changing one financial firm's business model. And yet, that may still be convenient if there are "bumps" in the regulations. See infra Sections III.E and IV.

${ }^{68}$ See Battiston et al., supra note 46 (first introducing the DebtRank indicator). Note that the literature has developed indicators that attempt to address the same question without network theory. For instance, in a widely cited article Adrian and Brunnermeier developed the CoVar, defined as "the change in the value at risk of the financial system conditional on an institution being under distress relative to its median state.” Tobias Adrian \& Markus K. Brunnermeier, CoVaR, 106 AM. ECON. REV. 1075, 1075 (2016). Economists have noted that such approaches, while certainly useful, should be either upgraded to account for network effects (see e.g. Nikolaus Hautsch, Julia Schaumburg \& Melanie Schienle, Financial Network Systemic Risk Contributions, 19 REV. FIN. 685, passim (2014)), or at least complemented by network measures (see e.g Francis X. Diebold \& Kamil Y1lmaz, On the Network Topology of Variance Decompositions: Measuring the Connectedness of Financial Firms, 182 J. ECONOMETRICS 119 (2014)). 
big to fail." ${ }^{69}$ Second, DebtRank builds on a rich tradition of studies on centrality measures for complex networks ${ }^{70}$ and has been extensively used and tested in the literature. ${ }^{71}$ However, calculating DebtRank requires relatively detailed information on the structure of the network. ${ }^{72}$ Because confidentiality constraints limit the availability of this kind of data, only the regulator can reliably calculate the DebtRank of a SIFI. ${ }^{73}$

Meanwhile, the Contagion Index attempts to capture the likelihood of failure of an institution and the impact that such failure would have on the financial system. ${ }^{74}$ The key factors that enter in the calculation of the Contagion Index "are the asset size of a financial institution, its leverage, and a connectivity measure that is given by the fraction of a financial institution's liabilities held by other financial institutions." 75 The main advantage of the Contagion Index is that it requires little information about the structure of the network, and hence it can be calculated using relatively easy-to-obtain data. ${ }^{76}$ At the same time, however, the Contagion Index cannot precisely capture the effects produced by important features of the network structure, exactly because it relies on such coarse information. For example, a key determinant of the contagiousness of a node is how well-connected its neighbors are. This dimension is only captured by recursive indicators such as the DebtRank. ${ }^{77}$

This brief discussion should be sufficient to convey the idea that many ways exist to calculate the systemic relevance of an institution, each with its own strengths and weaknesses. In other words, no perfect measure exists: if anything,

\footnotetext{
${ }^{69}$ Battiston et al., supra note 46.

${ }^{70}$ See e.g. Lawrence Page et al., The PageRank Citation Ranking: Bringing Order to the Web, Stanford InfoLab (1999), http://ilpubs.stanford.edu:8090/422/ (describing the Google PageRank algorithm).

${ }^{71}$ See e.g. Stefan Thurner \& Sebastian Poledna, DebtRank-Transparency: Controlling Systemic Risk in Financial Networks, 3 SCI. REP. 1888 passim (2013); Marco Bardoscia et al., DebtRank: A Microscopic Foundation for Shock Propagation, 10 PLOS ONE e0130406 passim (2015); Marco Bardoscia et al. Distress Propagation in Complex Networks: The Case of Non-Linear Debtrank, 11 PLOS ONE e0163825 passim (2016).

${ }^{72}$ Battiston et al. supra note 46, at 4-5 (describing how to calculate the DebtRank).

${ }^{73}$ Thurner \& Poledna, supra note 71 , at 3 (remarking that data to calculate the DebtRank is not publicly available but also that "in many countries central banks have all the necessary data to compute the DebtRank").

${ }^{74}$ Paul Glasserman \& H. Peyton Young, How Likely Is Contagion in Financial Networks?, $50 \mathrm{~J}$. BANKING \& FIN. 50 383, passim (2015).

${ }^{75} \mathrm{Id}$., at 383.

${ }^{76}$ In particular, the Contagion Index only requires "three pieces of information about each node: its net worth, its outside leverage, and its financial connectivity. The outside leverage is the ratio of the node's assets outside the network to its net worth; its financial connectivity is the fraction of its liabilities held by other financial institutions" (Glasserman \& Young supra note 74, at 394).

${ }^{77}$ Vasco M. Carvalho, From Micro to Macro Via Production Networks, 28 J. ECON. PERSP. 23, 3637 (2014) (discussing the difference between measures of centrality that look only at the direct neighbors of a node and measures of centrality that look also at the connections that such neighbors have).
} 
systemic relevance is a multidimensional concept, ${ }^{78}$ and there are no straightforward ways to aggregate the different dimensions in a meaningful way. Though imperfect, however, these measures do capture important features of a financial network, and important properties of a specific institution. The centrality of an institution in a network might, for example, lead it to become "toointerconnected-to-fail." ${ }^{79}$ As we discuss in some more detail in Part III, policymakers should identify the most appropriate measure(s) of systemic relevance by looking at the specific characteristics of the regulation to be applied, its objectives, and the information available to both the regulator and the regulated.

\section{Resilience to Shocks: Density}

A second important concept to introduce is a network's density, which expresses the number of existing links over the total possible links. ${ }^{80}$ The density is zero in an empty network with no edges, whereas it is maximal in a complete network in which each node is connected with all the other nodes (Fig. 1). ${ }^{81}$
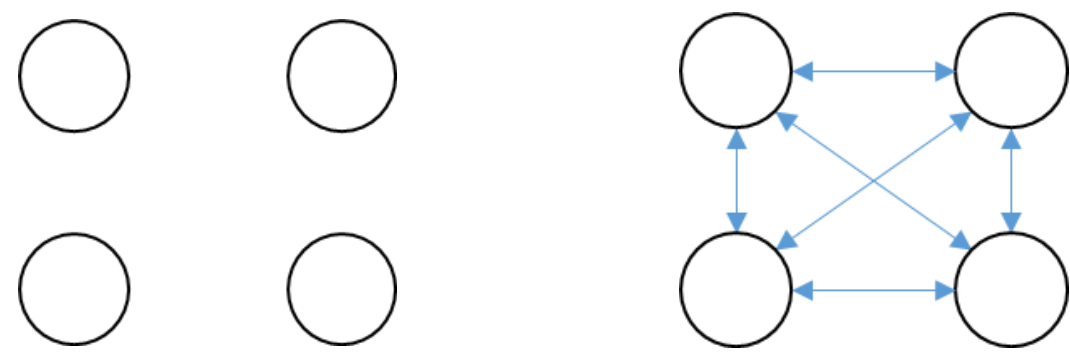

\section{Figure 1: An empty network (left panel) and a complete network (right panel).}

Economists have deeply explored the relationships between the density of the interconnections in the financial sector and the resilience of the system. A first strand of works argued that a more interconnected network is more resilient,

\footnotetext{
${ }^{78}$ See supra Part I. See also Robin L. Lumsdaine et al., The Intrafirm Complexity of Systemically Important Financial Institutions

(2016), https://papers.ssrn.com/sol3/papers.cfm?abstract_id=2604166.

${ }^{79}$ See e.g. Xavier Freixas, Bruno Parigi \& Jean-Charles Rochet Systemic Risk, Interbank Relations, and Liquidity Provision 32 J. MONEY, CREDIT \& BANKING 611 (2000) (showing that interbank credit extensions can cause institutions to become 'too interconnected to fail').

${ }^{80}$ MARK E. J. NEWMANN, NeTWORKS: AN INTROdUCTION 134 (2010).

${ }^{81}$ GOYAL, supra note 57, at 10.
} 
because the losses of one bank can be spread among more agents. ${ }^{82}$ Similarly, in a more interconnected network institutions benefit from the ability to use multiple funding sources, so that losing one funding source would not necessarily imperil the funded institution. In turn, this would allow the system to better absorb negative shocks. However, a second wave of studies suggested that the opposite relationship may hold. In more interconnected networks negative shocks can propagate more easily and harm larger portions of the economy. ${ }^{83}$

Recent studies have found that there is some truth to both claims, because financial contagion exhibits features akin to phase transition: ${ }^{84}$ like water changes from liquid to solid when the temperature falls to $32^{\circ} \mathrm{F}$, so financial systems change their properties when they become highly interconnected. More interconnected networks are more resilient to small shocks because small losses and risks can spread more easily. Yet, when losses are sufficiently large, "risk-sharing becomes risk-spreading," 85 as a dense web of interconnections facilitates the propagation of a negative shock. On the contrary, less interconnected networks are vulnerable to small shocks because the impact of such shocks cannot be distributed among the nodes. ${ }^{86}$ At the same time, however, large shocks are better contained within weakly interconnected networks because they do not propagate across the entire system as easily and are more likely to merely have a local impact. ${ }^{87}$ These tradeoffs raise questions about what network topology - or network structure - would best suit the financial system for the purpose of curbing systemic risk.

\section{Network-Sensitive Policies}

Building on insights from network theory, network-sensitive policies can be designed that explicitly account for the structure of the financial network and/or the patterns of interconnections among institutions. For instance, a network-sensitive

\footnotetext{
${ }^{82}$ See e.g. Freixas et al. supra note 79, at 613 (“interbank connections enhance the 'resiliency' of the system to withstand the insolvency of a particular bank, because a proportion of the losses on one bank's portfolio is transferred to other banks through the interbank agreements").

${ }^{83}$ See e.g. Larry Blume et al., Network Formation in the Presence of Contagious Risk, in PROCEEDINGS 12TH ACM CONFERENCE ON ELECTRONIC COMMERCE 1, 1 (2011).

${ }^{84}$ Acemoglu supra note 2, at 566; Prasanna Gai \& Sujit Kapadia, Contagion in Financial Networks, 466 PROCEEDINGS Royal Soc. LONDON A 2401, 2411-12 (2010).

${ }^{85}$ Andrew G. Haldane, Executive Director, Financial Stability, Bank of England, Why Institutions Matter (More than Ever), Speech at the Centre for Research on Socio-Cultural Change (CRESC) Annual Conference, School of Oriental and African Studies, London 3 (Sept. 4, 2013), available at https://www.bis.org/review/r130909b.pdf.

${ }^{86}$ Acemoglu supra note 2, at 566.

${ }^{87} \mathrm{Id}$.
} 
policy may factor in the financial shock that spreads to the financial network when a SIFI defaults to calibrate the constraints on that SIFI's behavior. ${ }^{88}$

Network-sensitive policies are most useful when the risks regulators are concerned about arise through the interaction of firms in the financial network, rather than depending only on atomistic factors, such as size, or macro factors, such as the credit cycle. The canonical example of risks arising from firms interconnections is systemic risk. ${ }^{89}$ Importantly, risks of this kind tend to scale nonlinearly, which rules based on atomistic parameters fail to catch. ${ }^{90}$ For example, as the financial network becomes more interconnected there are more links between institutions over which financial shocks can spread and amplify, so that large financial shocks will be less contained and much more harmful. ${ }^{91}$

In Sections II.A and II.B we have given examples of microprudential and macroprudential policies that were atomistic in content. These atomistic tools, however, have been recognized as offering only an incomplete answer to the networked risks that materialized in the financial crisis. Atomistic microprudential policies fail to account for the systemic risks that individual financial institutions can generate and are affected by, while atomistic macroprudential policies similarly ignore how financial shocks can propagate and amplify as they move through the financial network. In the remainder of this section, we report some examples of network-sensitive macroprudential policies that, since the crisis, academics and international rule setters have, respectively, put forth and endorsed various network-sensitive regulations, also accounting for the ones U.S. policymakers have implemented.

\footnotetext{
88 To be sure, we recognize that regulations may contain elements that cannot properly be classified as atomistic or network-sensitive. Capital requirements that, for example, vary in relation to the credit cycle (e.g. the countercyclical capital surcharge) are not fully atomistic but also do not fully take the structure of the financial network into account (rather, they focus only on some of its aggregate properties, like credit provision). For simplification, we exclude such considerations from our stylised characterisation. Our point is not to mathematically characterize financial regulation but instead simply to note that, in many cases, adding a network-sensitive element to an otherwise atomistic regulation will make it more effective in handling systemic risk.

${ }^{89}$ See generally Haldane \&. May, supra note 6 . Haldane and May liken the dynamics operating on financial network to those in 'ecological food webs' and 'networks in which infectious diseases spread'. See also Stefano Battiston et al., Complexity Theory and Financial Regulation, 351 SCIENCE 818, 818 (2016) ("[N] etwork topology and positions of banks matter; the global financial network may collapse even when individual banks appear safe.”).

${ }^{90}$ IAN GOLDIN \& MiKe MARIATHASAN, THE BUTTERFly DEFECT: HOW GlOBALIZATION CREATES SYSTEMIC RISKS, AND WHAT TO Do ABOUT IT 66 (3d ed. 2014) ("We now know that nodes of the financial network cannot be analyzed in an additive or linear manner. They cannot be isolated from their interactions with other links in the broader network. Systemic risk must examine nodes, pathways, and the relationships between them").

${ }^{91}$ See e.g. Allen \& Gale, supra note 33, at 23-27.
} 


\section{SIFI Designation}

A key post-crisis regulatory innovation has been the explicit recognition that some financial institutions are systemically important. At the international level, global SIFIs (hereinafter, "G-SIFIs") and, specifically, global systemically important banks (hereinafter, "G-SIBs") and global systemically important insurers are designated on a yearly basis by the relevant national authorities under the auspices of the Financial Stability Board (FSB), ${ }^{92}$ an organization that coordinates financial regulatory reform amongst the G-20 countries. ${ }^{93}$ To make this determination, the FSB has developed an assessment methodology that draws upon thirteen criteria categorized into five groups. ${ }^{94}$ Some of these, like a firm's size or a firm's complexity, ${ }^{95}$ are atomistic in nature. Others - substitutability, cross-jurisdictional activity and especially interconnectedness - explicitly derive a firm's importance from its position within the wider financial system: they are, in other words, network-sensitive. ${ }^{96}$ For banks, these criteria have been developed by the Basel Committee on Banking Supervision, which states in its guidance: "[f]inancial distress at one institution can materially increase the likelihood of distress at other institutions given the network of contractual obligations in which these firms operate. A bank's systemic impact is likely to be positively related to its interconnectedness vis-à-vis other financial institutions." 97

The way the interconnectedness criterion has been operationalized somewhat qualifies the commitment to network-sensitivity, though. The indicators used to evaluate interconnectedness - such as the value of a firm's intra-financial

${ }^{92}$ For 2018, see Financial Stability Board, 2018 List of Global Systemically Important Banks (GSIBs) (November 2018), available at http://www.fsb.org/wp-content/uploads/P161118-1.pdf.

${ }^{93}$ See Stavros Gadinis, The Financial Stability Board: The New Politics of International Financial Regulation 48 TEX. INT'L L.J. 157 passim (2013) (providing an overview of the FSB and its role in international financial regulation).

${ }^{94}$ Basel Committee on Banking Supervision, Global Systemically Important Banks: Revised Assessment Methodology and Higher Loss Absorbency Requirement, at 5 (July 2018), available at https://www.bis.org/bcbs/publ/d445.pdf.

${ }^{95}$ To operationalize the idea of a firm's complexity, U.S. regulators look at the notional amount of over-the-counter derivatives and total "level 3 assets" a firm holds: 12 C.F.R. $\$ 217.404$ (2018).

${ }^{96}$ The criteria of substitutability (that is, whether the functions an institution performs can easily be taken over by another firm) and cross-border activity also refer to characteristics of the financial network, but do not explicitly use network metrics. A bank that is highly substitutable, for example, fulfils a role in the financial network that other banks could take over. In network terms, this would suggest that the node representing that bank could easily be replaced without disconnecting the network. When a bank has significant cross-border activity, it is in a position to link the domestic financial network with the international financial network (or, at least, the network in a different jurisdiction), and therefore to act as a conduit for financial shocks.

${ }_{97}$ Basel Committee on Banking Supervision Global Systemically Important Banks, 6 (table 1) (July 2013), available at https://www.bis.org/publ/bcbs255.pdf (emphasis added). 
system assets and liabilities and outstanding securities ${ }^{98}$ - are merely sums of the relevant exposures. Using such sums tells us something about a firm's aggregate exposures to the financial network as a whole but obscures the more granular details of the network structure because the exposures are not broken down to individual institutions. Such details may matter, for example because some types of links between two firms are more salient than others, or because the clustering of a group of firms can create cyclical structures that help propagate shocks. ${ }^{99}$ Nevertheless, and implementation details aside, the important observation for our purposes is that the designation of G-SIFIs is explicitly and deliberately network-sensitive.

National regulators retain discretion to set stricter standards for G-SIFIs operating in their jurisdiction, and to designate SIFIs that are domestically systemically important. ${ }^{100}$ In doing so, they are encouraged (but not required) to follow the principles used by the FSB to identify G-SIFIs. ${ }^{101}$ In the U.S., non-bank financial institutions can be designated as SIFIs by the Financial Stability Oversight Council (FSOC), the new regulatory body created under Title I of the Dodd-Frank Act. ${ }^{102}$ In making this designation, the FSOC largely follows the criteria established by the FSB, including the network-sensitive criterion of interconnectedness. ${ }^{103}$ It also takes account of the "extent and nature of the transactions and relationships of the company with other significant non-bank financial companies and significant bank holding companies". ${ }^{104}$ Notably, the FSOC can apply these criteria - as well as others ${ }^{105}$ - holistically and is not bound by a single measurement metric.

\footnotetext{
${ }^{98}$ For banks, see ibid.

99 The situation is similar for the slightly different assessment methodology developed by the International Association of Insurance Supervisors (IAIS) for insurers, which also considers interconnectedness as one of its categories. See IAIS Global Systemically Important Insurers: Updated Assessment Methodology (2016) https://www.iaisweb.org/page/supervisorymaterial/financial-stability-and-macroprudential-policy-and-surveillance//file/61179/updated-g-siiassessment-methodology-16-june-2016 (table 2, page 14).

${ }^{100}$ In the case of banks, see Basel Committee on Banking Supervision A Framework for Dealing with Domestic Systemically Important Banks, at 6 (July 2012), available at https://www.bis.org/publ/bcbs233.htm.

${ }^{101}$ For banks, see ibid., at 1-2.

102 Dodd-Frank Wall Street Reform and Consumer Protection Act, Pub. L. No. 111-203 (hereafter “Dodd-Frank Act"), $\S 111,124$ Stat. 1392 (2010), 12 U.S.C. $\S 5321$ (2017). The aim of this authority includes to "identify risks to the financial stability of the United States" and "respond to emerging threats to the stability of the United States financial system." See Dodd-Frank Act, § 112(a)(1), 12 U.S.C. § 5322(a)(1) (2017).

${ }^{103}$ Dodd-Frank Act, $\S 113(a)(1)-(2), 12$ U.S.C. $\S 5323(a)(1)-(2)$ (2017). For an overview of the designation process, see Robert F. Weber, The FSOC's Designation Program as a Case Study of the New Administrative Law of Financial Supervision, 36 YALE J. ON REG. 359, 388-394 (2018).

${ }^{104}$ Dodd-Frank Act, § 113(a)(2)(C), 12 U.S.C. § 5323(a)(2)(C) (2017).

105 The list of criteria is non-exhaustive. See Dodd-Frank Act, § 113(a)(2)(K), 12 U.S.C. $\S$ 5323(a)(2)(K) (2017).
} 
Similarly, the Federal Reserve Board of Governors can designate any U.S. bank with assets over \$50bn as a SIB after considering the same criteria. ${ }^{106}$

Generally, then, the designation of SIFIs is an example of a networksensitive policy, given that it also takes the firm's role and position within the network that makes up the financial system into account. The outcome of the assessment is binary: only if a firm's score crosses a certain regulatory threshold, will it be regarded as a SIFI. Once a firm has been designated as a SIFI, it becomes subjected to more stringent financial regulation and supervision. The additional regulation, however, remains atomistic in nature. More precisely, its stringency may increase as certain firm-specific (atomistic) risk factors increase, and contentwise it is not network-sensitive.

\section{The Risk-Based Capital Surcharge}

A few examples exist of SIFI-specific regulations that complement atomistic regulatory principles with network-sensitive policies.

The most explicit example of such type of regulation is the risk-based capital surcharge, part of Basel III ${ }^{107}$ and implemented by Section 165 of the Dodd-Frank Act. ${ }^{108}$ As discussed above, ${ }^{109}$ highly interconnected institutions can transmit shocks widely throughout the financial system, potentially causing significant losses that may impair the financial system and the wider economy. As the then Vice-Chair of the Federal Reserve, Janet Yellen, observed in 2013:

"[W]hen Lehman Brothers failed, the shock was transmitted through money market mutual funds to the short-term funding and interbank markets. While some participants in each of these sectors had direct exposures to Lehman, many more did not. Moreover, even in cases in which direct exposures to Lehman were manageable, the turmoil caused by Lehman's failure added stress to the system at a particularly unwelcome time. In this way, the failure of a highly interconnected institution such as Lehman imposes costs on society well in excess of those borne by the firm's shareholders and direct creditors." 110

Yellen concluded that "tying enhanced capital requirements to interconnectedness improves the resilience of the system." "111 The risk-based capital surcharge is designed to do exactly that. This surcharge, which constitutes an

\footnotetext{
106 Dodd-Frank Act, $§ 121,12$ U.S.C. $§ 5331$ (2017).

${ }^{107}$ Basel Committee on Banking Supervision, supra 9496, at 10-11.

10812 C.F.R. $\$ 217$ Subpart H (2018).

109 See supra, Section II.B.2.

110 Yellen, supra note 4.

${ }^{111}$ Id. See also Prasanna Gai, Andrew Haldane \& Sujit Kapadia, Complexity, Concentration and Contagion, 58 J. MONETARY ECON., 453 (2010) (finding that surcharges for systemically important financial institutions could make the financial system more resilient).
} 
additional capital requirement specifically for G-SIBs, is not uniformly applied to all G-SIBs but instead ranges from 1 to 3.5 percent (divided into 'buckets' of 0.5 percent) depending on the systemic importance of the G-SIB; ${ }^{112}$ the more systemically important a firm, the higher the surcharge. ${ }^{113}$ Systemic importance is assessed using a methodology that is similar to that used by the Basel Committee on Banking Supervision to designate SIFIs, and includes the same interconnectedness measures. ${ }^{114}$ Using this methodology, JP Morgan Chase is, for instance, subjected to the highest capital surcharge of all assessed U.S.-based GSIBs (2.5\%), while Bank of New York Mellon, Morgan Stanley and State Street are subject to the lowest $(1 \%) .{ }^{115}$ The surcharge is an example of a genuinely network-sensitive regulation, because (all else being equal) a higher interconnectedness score results in a more stringent capital requirement.

\section{Stress Tests}

Stress tests assess the resilience of an individual institution, a set of similar institutions (e.g. banks), or the financial sector as a whole by devising a hypothetical (but plausible) stress scenario and determining the losses that would ensue for the relevant component if it materializes. ${ }^{116}$ Individual institutions pass a stress test if, after being subjected to the stress scenario, they 'survive' as a going concern, that is, if their capital and liquidity levels are calculated to stay above a certain minimum threshold set by the regulator. If an institution fails the stress tests, regulators can subject it to stricter supervision and require it to improve capital ratios (including by restricting shareholder dividends and share repurchases), increase liquidity or divest certain business units. ${ }^{117}$ The objective of such stress tests is to ensure that financial institutions hold enough capital and liquidity to withstand adverse financial conditions and that the financial system as a whole is sufficiently resilient.

${ }^{112}$ Dodd-Frank Act, § 165(a)(2)(A), 12 U.S.C. § 5365(a)(2)(A) (2017) (tailored application of the surcharge).

${ }^{113}$ See e.g. Lael Brainard, supra note 34 :

The capital surcharge is designed to build additional resilience and lessen the chances of an institution's failure in proportion to the risks posed by the institution to the financial system and broader economy. (...) The capital surcharge should help ensure that the senior management and the boards of the largest, most complex institutions take into account the risks their activities pose to the system.

${ }^{114}$ For the methodology, see Basel Committee on Banking Supervision, supra 94 at 10-11.

115 Financial Stability Board, 2018 List of Global Systemically Important Banks (G-SIBs) (16 November 2018), available at http://www.fsb.org/2018/11/2018-list-of-global-systemicallyimportant-banks-g-sibs/ .

116 See Aymanns et al., supra note 3, at 357-358.

117 Regulation YY, 12 C.F.R. § 252 (2018). 
Following the implementation of the Dodd-Frank Act, U.S. bank holding companies with consolidated assets of over $\$ 50 \mathrm{bn}$ as well as certain non-bank financial institutions undergo Federal Reserve Board-led annual stress tests, known as the Dodd-Frank Annual Stress Test and the Comprehensive Capital Analysis and Review. ${ }^{118}$ Stress tests started out as purely atomistic exercises, essentially modelling each bank as if it operated in isolation. ${ }^{119}$ Although U.S. regulators have increasingly flirted with network theory, U.S. regulatory stress tests still (largely) rely on atomistic models that barely take network properties into account, if at all. ${ }^{120}$

The trend in research and regulatory model development, however, is decidedly headed towards more network-sensitive stress tests. ${ }^{121}$ More precisely, the most recent stress test methodologies take the interactions between an individual institution and the rest of the system following a (hypothetical) shock into account: in particular, both network topologies and network dynamics are factored in to calculate the relevant feedback effects. ${ }^{122}$ Outside of the U.S., various regulators have already incorporated these network-sensitive methods in supervisory stress tests. ${ }^{123}$ If well carried out, the move towards network-sensitive stress tests will not only elucidate how shocks can propagate through financial networks but will also enable regulators to levy higher capital and liquidity requirements and exercise stricter supervision on institutions that contribute disproportionally to systemic risk within the financial system.

118 Dodd-Frank Act, § 165(i)(1), 12 U.S.C. § 5365(i)(1) (2017) (Dodd-Frank Annual Stress Test); 12 C.F.R. 225.8 (2018) (Comprehensive Capital Analysis and Review).

119 Aymanns et al., supra note 3, at 360-367.

120 See e.g. Jill Cetina, Mark Paddrik, Sriram Rajan Stressed to the Core: Counterparty Concentrations and Systemic Losses in CDS Markets, 35 J. FIN. STABILITY 38, 39 (2018) (noting that "network methods have not been applied so far in supervisory stress tests in the United States"). ${ }^{121}$ See generally Aymanns et al., supra note 3, at 382-384; Ron Anderson et al., Macroprudential Stress Tests and Policies: Searching for Robust and Implementable Frameworks (2018).

122 See e.g. Stefano Battiston \& Serafin Martinez-Jaramillo, Financial Networks and Stress Testing: Challenges and New Research Avenues for Systemic Risk Analysis and Financial Stability Implications 35 J. FIN. STABILITY 6, at 8 (2015) (noting that network models are now important components of stress testing frameworks, and that network models can be used to integrate liquidity and solvency interactions); Fabio Caccioli, Paolo Barucca \& Teruyoshi Kobayashi, Network Models of Financial Systemic Risk: A Review 1 J. COMPUTATIONAL SoC. SCI. 81, at 105 (2018) (noting that measuring and analyzing the structure of interbank networks is critical to understanding how local risks can spread over the entire network and how systemic risk may evolve over time).

${ }^{123}$ See European Central Bank, A Macro Stress-Testing Framework for Bank Solvency Analysis Monthly Bulletin (August 2013), available at https://bfi.uchicago.edu/research/publishedresearch/macro-stress-testing-framework-bank-solvency-analysis; Bank of Korea, Financial Stability Report (October 2012), available at https://www.bok.or.kr/eng/bbs/E0000737/view.do?nttId=184539\&menuNo=400219; $\quad$ Kartik Anand, Guillaume Bédard-Pagé \& Virginie Traclet, Stress Testing The Canadian Banking System: A System-Wide Approach, 61 BANK OF CANADA FINANCIAL STABILITY REV., at 63 (2014) (outlining the MacroFinancial Risk Assessment Framework stress testing approach developed by the Bank of Canada, and noting that it incorporates network spillover effects). 


\section{Optimal Network Topology Design Policies}

Section II.B highlighted that financial networks can have different network topologies, ${ }^{124}$ and that the optimal topology for financial networks from the perspective of systemic risk is widely debated and still unclear. ${ }^{125}$ Each network topology comes with its specific costs and benefits. In the context of systemic risk, the trade-off is commonly presented as one between strongly interconnected networks that can better deal with small shocks by spreading the risk across many players, and weakly interconnected networks that can contain larger shocks. Despite this lack of certainty around optimal topologies, scholars and regulators alike have made attempts to move the system towards a network topology they consider superior to the status quo from the perspective of systemic risk.

This logic underpins two of the Dodd-Frank Act's reforms. First, the requirement to centrally clear over-the-counter derivatives ${ }^{126}$ can be seen as a conscious attempt to alter the topology of the derivatives market: by introducing a central counterparty, complicated mesh network structures are transformed into dramatically simpler hub-and-spoke ones. ${ }^{127}$ Second, the Dodd-Frank Act requires the Federal Reserve Board, before authorizing a concentration in the banking sector, to consider "the extent to which a proposed acquisition, merger, or consolidation would result in greater or more concentrated risks to the stability of the United States banking or financial system." 128 As part of this exercise, the Federal Reserve uses similar criteria as those developed for the designation of SIBs, including the network-sensitive interconnectedness criterion. ${ }^{129}$

While policy measures like the two described immediately above have focused on general features of financial networks, recent research has moved beyond such stylized approaches to examine systemic risk in more realistic settings based on detailed contract-level data. For example, Sebastian Poledna and Stefan

\footnotetext{
${ }^{124}$ For example, the U.S. banking system has consolidated since the 1980s as interstate banking restrictions were dropped and the Glass-Steagall Act was gradually abandoned, but it is still far less concentrated than the banking system in the United Kingdom, where a few banks hold the majority of retail deposits. See BARR ET AL., supra note 30, at 735.

${ }^{125}$ See e.g. Matthew Elliott, Benjamin Golub \& Matthew O Jackson, Financial Networks and Contagion 104 Am. Econ. Rev. 3115 (2014); Joseph E Stiglitz, Risk and Global Economic Architecture: Why Full Financial Integration May Be Undesirable 100 AMERICAN ECONOMIC REVIEW: PAPERS AND PROCEEDINGS 388 (2010) (noting that, in the extreme, autarky may be superior to full integration); Nimalan Arinaminpathy, Sujit Kapadia \& Robert M. May, Size and Complexity in Model Financial Systems 109 PROCEEDINGS OF THE NATIONAL ACADEMY OF SCIENCES O FTHE UNITED STATES OF AMERICA (PNAS) 18338-18343 (2012).

${ }^{126}$ Dodd-Frank Act, Title VII (codified as amended in scattered sections of 15 U.S.C. and 7 U.S.C.).

${ }^{127}$ Yellen, supra note 4.

${ }^{128}$ Dodd-Frank Act, § 604(d), 12 U.S.C. § 1842(c)(7) (2017).

${ }^{129}$ Dodd-Frank Act, $\S 121(\mathrm{c}), 12$ U.S.C. $\S 5331(\mathrm{c})(2017)$.
} 
Thurner argue that it is also possible to quantify the share of total systemic risk contributed by any individual liability within the system. Leveraging on this information, they propose to introduce a systemic risk tax for each financial transaction, calculated on the basis of various network properties that would increase with the marginal systemic risk resulting from that transaction. As they argue, such a network-sensitive Pigouvian tax, designed to internalize some of the costs associated with systemic risk, would trigger a bottom-up reorganization of the topology of the financial system that would substantially lower systemic risk. ${ }^{130}$

Such approaches, even if they are at an early stage, open the door to a wider suite of network-sensitive topology regulations. Large exposure limits, for example, which put a ceiling on the maximum exposure one institution may have to another, ${ }^{131}$ already affect the topology of networks but are currently not networksensitive. In principle, that could easily change by lowering the allowed maximum exposures as counterparties become more central in the network. This would be in keeping with the objective of large exposure rules to reduce systemic risk associated with a concentration of risks. ${ }^{132}$ Similarly, the rules on internal ratings-based models used to calculate how much capital a bank should hold against a certain (credit or market risk) exposure ${ }^{133}$ could be made network-sensitive. All else equal, this would require banks to hold more capital for exposures to counterparties that are more central in the financial network. In a companion paper, we will explore such network-sensitive topology regulation in greater depth.

\section{Conclusion: A Stylized Taxonomy of Prudential Regulation}

In the previous sections, we have reviewed microprudential and macroprudential rules and introduced the distinction between atomistic and network-sensitive ones. Using these classifications, we can divide policies into four categories (see table 1). Atomistic microprudential rules represent the conventional pre-crisis rules, like capital and liquidity requirements. Following the crisis, some macroprudential policies were implemented through the tools of microprudential regulation. For example, a countercyclical capital buffer, which increases in times of economic growth to "lean against the credit cycle" and prevent asset price bubbles, ${ }^{134}$ was implemented as part of the capital regulation framework. Similarly, loan-to-value ratios are macroprudential in that they are designed to constrain excessive credit

\footnotetext{
${ }^{130}$ Sebastian Poledna \& Stefan Thurner, Elimination of Systemic Risk in Financial Networks by Means of a Systemic Risk Transaction Tax, 16 QUANTITATIVE FIN. 1599 passim (2016).

${ }^{131}$ Dodd-Frank Act, $\S 165(\mathrm{e}), 12$ U.S.C. $\$ 5365(\mathrm{e})(2017)$.

132 Dodd-Frank Act, $\S 165(\mathrm{e}), 12$ U.S.C. $§ 5365(\mathrm{e})(1)(2017)$.

${ }^{133}$ Regulation Q - 12 CFR $\S 217(\mathrm{E})$.

${ }^{134}$ Cf. Tarullo, supra note 29, at 507 (distinguishing "lean-against-the-wind" macroprudential measures from those "designed to increase the resiliency of the financial system should systemic risk nonetheless build sufficiently that broad-based stress ensues").
} 
growth in the financial system, but they are atomistic, because they are not sensitive to network properties.

Insofar as they factor in interconnections among firms within the financial system, as we have seen, ${ }^{135}$ the SIFI designations, risk-based capital surcharges and the system-wide stress tests that are being developed are network-sensitive (and macroprudential).

\begin{tabular}{|l|l|l|}
\hline \multicolumn{1}{|c|}{ Target/Network } & Atomistic & Network-Sensitive \\
\hline Microprudential & $\begin{array}{l}\text { Atomistic } \\
\text { microprudential } \\
\text { (e.g. capital } \\
\text { requirements, liquidity } \\
\text { requirements, } \\
\text { corporate governance) }\end{array}$ & $\begin{array}{l}\text { Network-sensitive } \\
\text { microprudential }\end{array}$ \\
\hline Macroprudential & $\begin{array}{l}\text { Atomistic } \\
\text { macroprudential } \\
\text { (e.g. countercyclical } \\
\text { capital buffer, loan-to- } \\
\text { value ratios, firm-level } \\
\text { stress tests })\end{array}$ & $\begin{array}{l}\text { Network-sensitive } \\
\text { macroprudential } \\
\text { (e.g. risk-based capital } \\
\text { surcharge, SIFI- } \\
\text { designations, system- } \\
\text { wide stress tests) }\end{array}$ \\
\hline
\end{tabular}

Table 1: A stylized taxonomy of prudential policies.

To the best of our knowledge, there are no examples of implemented, or even proposed, network-sensitive microprudential tools: Part III shows how regulations addressing SIFIs' governance can be tweaked to fill this void, with a particular focus on managers' liability, managers' compensation and shareholder rights in mergers between a sound SIFI and a failing one. The turn to networksensitive regulation, one of the key innovations introduced after the financial crisis, has so far not reached governance regulations. We argue that it should. Though we remain agnostic as to whether any of the specific governance requirements we focus on would be desirable, we argue that making them network-sensitive will allow regulators to better mitigate systemic risk.

${ }^{135}$ See supra Section II.D. 


\section{NETWORK-SENSITIVE SIFI GOVERNANCE REQUIREMENTS: HOW IT WOULD WORK}

Part II has shown that although policymakers have started making use of policies based on network theory tools, we are still in early days and, to our knowledge, no attempt has yet been made to apply the same approach to the regulation of banks' and SIFIs' governance. This may in fact run counter to the intuition that governance rules are quintessentially atomistic in nature. Yet, as we have seen, macroprudential policies themselves often boil down to measures applying to individual institutions. In this vein, we argue here that policies that are meant to reduce systemic risk by making SIFIs' governance and management less prone to excessive risk-taking would improve by integrating them with network-sensitive elements. We illustrate this general point with examples of SIFI-focused policy proposals and solutions relating to three core corporate governance issues, namely directors' liability, executive compensation and shareholder voting. Before doing so, however, we clarify the special nature of SIFI governance and why it may warrant specific policies to reduce systemic risk.

\section{A. Corporate vs SIFI Governance}

In essence, the traditional corporate governance paradigm has three main pillars: shareholders elect directors; ${ }^{136}$ directors hire and monitor managers; ${ }^{137}$ and managers manage the company in the interest of shareholders. ${ }^{138}$ Corporations governed in such a way should keep agency costs under control and, net of externalities, ensure that, together with shareholders' welfare, societal welfare is

\footnotetext{
136 See e.g. ROBERT C. ClARK, CORPORATE LAW 94 (1986).

${ }^{137}$ See e.g. Jeffrey N. Gordon, The Rise of Independent Directors in the United States, 1950-2005: Of Shareholder Value and Stock Market Prices, 39 STAN. L. REV. 1465, 1472-99 (2007).

138 See e.g. William T. Allen ET AL., COMMENTARIES AND CASES ON THE LAW OF BuSINESS ORGANIZATION 284 ( $5^{\text {th }}$ ed. 2016) ("That director loyalty to the 'corporation' is, ultimately, loyalty to equity investors is an important theme of U.S. corporate law"); Henry Hansmann \& Reinier Kraakman, The End of History for Corporate Law, 89 GEO. L.J. 439, 441 (2001):
}

[T] here is today a broad normative consensus that shareholders alone are the parties to whom corporate managers should be accountable, resulting from widespread disenchantment with a privileged role for managers, employees, or the state in corporate affairs. This is not to say that there is agreement that corporations should be run in the interests of shareholders alonemuch less that the law should sanction that result. ... The point is simply that now, as a consequence of both logic and experience, there is convergence on a consensus that the best means to this end (that is, the pursuit of aggregate social welfare) is to make corporate managers strongly accountable to shareholder interests and, at least in direct terms, only to those interests. 
also maximized. ${ }^{139}$ While, of course, negative externalities cannot be assumed away, the prevailing view has tended to be that, rather than by tweaking corporate governance arrangements, externalities are better dealt with via specific regulations addressing the corporate business they result from. ${ }^{140}$ In other words, it is broadly accepted that the incentives of managers, boards and shareholders are, overall, the most appropriate for society as a whole, and that business sector-specific measures are to be preferred to changing how corporate governance works across the board. ${ }^{141}$

Such a paradigm is increasingly under attack, ${ }^{142}$ but what matters most here is that the financial crisis has already turned it on its head with regard to systemically important banks and financial institutions. ${ }^{143}$ The reasoning is as follows: highly leveraged financial institutions, with a maturity and liquidity mismatch between the assets and liabilities in their balance sheets, are structurally fragile and prone to depositors' (and other short-term creditors') runs. ${ }^{144}$ Given the interconnectedness of financial institutions and their opaque assets, a run on an

139 See e.g. Milton Friedman, The Social Responsibility of Business Is to Increase Its Profits, N.Y. TIMES MAG., Sept. 13, 1970, at 32, reprinted in CORPORATE ETHICS AND CORPORATE GOVERNANCE 173-78 (Walther C. Zimmerli, Klaus Richter \& Markus Holzinger eds., 2007). This view, which has always been far from undisputed (see e.g. Lynn A. Stout, Bad and Not-So-Bad Arguments for Shareholder Primacy, 75 SOUTH. CAL. L. REV. 1189 (2001)), is being increasingly questioned (most recently, see Oliver Hart \& Luigi Zingales, Companies Should Maximize Shareholder Welfare Not Market Value, 2 J.L. FIN. \& ACCT. 247 (2017); COLIN MAYER, PROSPERITY 36-37 (2018)), but the terms and implications of the current debate are out of the scope of this article.

140 See e.g. Michael C. Jensen, Value Maximization, Stakeholder Theory, and the Corporate Objective Function, 22 J. APPLIED CORP. FIN., Fall 2001, at 8, 11, 16.

141 See e.g. FranK H. EASTERBROOK \& DANIEL R. Fischel, ThE ECONOMIC STRUCTURE OF CORPORATE LAW 68 (1983); Jonathan R. Macey, An Economic Analysis of the Various Rationales of Making Shareholders the Exclusive Beneficiaries of Corporate Fiduciary Duties 21 STETSON L. REV. 23 (1992). But see Henry Hansmann \& Reinier Kraakman, Toward Unlimited Shareholder Liability for Corporate Torts, 100 YALE L.J. 1879 (1990) (arguing that shareholders have incentives to produce negative externalities due to limited liability).

142 See supra note 139.

143 See e.g. Armour \& Gordon, supra note 12, at 50-56; Mark Roe, Structural Corporate Degradation Due to Too-Big-To-Fail Finance, 162 U. PENN. L. REV. 1419 passim (2014) (arguing that the funding benefit large banks receive by being seen as 'too big to fail' creates incentives for banks to expand beyond their socially optimal size); Jill E. Fisch, The Mess at Morgan: Risk, Incentives, and Shareholder Empowerment, 83 U. CIN. L. REV. 651 (2015) (arguing that JP Morgan's 'London Whale' trades demonstrate limitations on the value of shareholder empowerment in addressing the public impact of the corporation, because it highlights that shareholder incentives are not fully aligned with the interests of non-shareholder stakeholders); Thom Wetzer, In Two Minds: The Governance of Ring-Fenced Banks, 19 J. CORP. L. STUD. 197, 198-201 (2018) (arguing that moral hazard resulting from shareholder primacy coupled with systemic riskiness may lead bank managers to take excessive risks and undermine ring-fencing regulation designed to curtail such practices).

${ }^{144}$ See e.g. Hyun S. Shin, Reflections on Northern Rock: The Bank Run that Heralded the Global Financial Crisis, 23 J. ECON. PERSP. 101 passim (2009). 
individual bank may easily propagate to other banks, causing (potentially systemwide) contagion that, in the worst case scenario, may bring down the financial system ${ }^{145}$ and create havoc throughout the entire economy. ${ }^{146}$ While governments attempt to prevent depositors' runs through deposit insurance and other regulations aimed at ensuring the safe and sound conduct of banks' business, such measures are not fail-proof. At points when large banks have been close to insolvency, governments have tended to play it safe: to avoid the risks arising from their insolvency for the system as a whole, they have injected enough government money into them to prevent them from going bankrupt.

Combining the expectation of government support with shareholder primacy leads to trouble. Shareholders benefit from maximizing the expected value of the government subsidy, which can be done by taking on more risk than is socially optimal, increasing leverage and size, and gaining centrality in the financial network: the riskier they are for the financial system as a whole, the greater the likelihood that they will be treated as too-big- and/or too-interconnected-to-fail, which in turn lowers the SIFI's cost of financing. ${ }^{147}$ Shareholder-oriented governance and market pressures compel managers to act accordingly. ${ }^{148}$ Creditors, in turn, not only accept a lower interest rate but also have weaker incentives to monitor the SIFI and discipline bank managers, relying as they can on free government insurance. ${ }^{149}$

As an outcome, in good times SIFI shareholders (and managers with equitybased compensation packages) enjoy the gains from higher share prices. In bad times, either the SIFI close to insolvency is bailed out according to expectations or, like in the Lehman Brothers case, it fails with potentially doomsday consequences for the financial system: in either case, shareholders cannot lose more than they paid for their shares, given their limited liability, while the additional harm is suffered by taxpayers or by creditors and other participants in the collapsed financial system.

\footnotetext{
145 See e.g. Sylvain Benoit, Jean-Edouard Colliard, Christophe Hurlin \& Christophe Pérignon, Where the Risks Lie: A Survey on Systemic Risk, 21 REV. FIN. 109 (2017).

146 See e.g. Christopher James, The Losses Realised in Bank Failures 46 J. FIN. 1223 (1991).

${ }^{147}$ See e.g. Adam J. Levitin, In Defense of Bailouts, 99 GEO. L.J. 435, 439 (2011) ("if either or both creditors and shareholders of such a TBTF [Too-big-to-fail] institution believe they will be made whole in a bailout - or not bear all the losses - they will have a reduced incentive to monitor the TBTF institution's risk-taking, and they will not demand as great of a risk premium when they extend credit").

148 See e.g. Alan D. Morrison, Systemic Risks and the "Too-Big-To-Fail” Problem, 27 OXFORD REV. ECON. POL'Y 498 (2011).

${ }^{149}$ Armour \& Gordon, supra note 12, at 45 ("The effect of bailouts is to provide ex post insurance to nondepositor creditors of banks. Such creditors anticipate the provision of insurance, even if no explicit guarantees are made, in turn reducing the borrowing costs systemically important banks have to pay to engage in risk-taking").
} 
Given these problems, scholars and policymakers have attempted to devise solutions to ameliorate the incentives of SIFI managers, directors and shareholders, ranging from an enhanced liability regime to constraints on compensation schemes and limits to shareholder powers. In the next sections we give concrete examples of how network theory can be used to aid policymakers in such an endeavor.

\section{B. Personal Liability of Directors and Managers}

In this section we show that a network-sensitive liability regime is superior to an atomistic one in inducing SIFIs' managers and directors to account for the systemic relevance of their firm when making management and strategy decisions. To illustrate this point, we take John Armour and Jeffrey Gordon's proposal to tighten SIFI officers' and directors' liability for excessive risk-taking ${ }^{150}$ and show how the addition of a network-sensitive component makes the rule more effective. Note that, in doing so, we take no position on whether a liability regime along the lines of Armour and Gordon's proposal would bring net societal benefits. ${ }^{151}$

Armour and Gordon's proposal addresses the following scenario: assume that a SIFI manager must decide whether to invest in a given project. Assume further that the project has a 0.9 probability of success and - if successful - yields a gain of $\$ 100$. Further, assume that a negative outcome would entail a loss of $\$ 100$ for the SIFI. A manager whose interests are aligned with those of shareholders will invest in the project. Now, let us also assume that, due to contagion effects, if the project fails it will cause losses for third parties (a "systemic harm," in Armour and Gordon's words) equal to $\$ 3,000$. Because of incentive alignment via stock options and in the absence of a liability regime that makes directors and officers liable for the systemic harm they may cause, managers are likely to invest in the project without worrying about the impending systemic harm. ${ }^{152}$ To address this problem, Armour and Gordon propose a negligence-based liability rule for SIFI managers and directors. ${ }^{153}$ In this section, we show that the liability rule that they propose and, more generally, any non-network-sensitive liability rule for SIFI managers' and directors' liability - would fail to induce managers and directors of SIFIs to

\footnotetext{
${ }^{150}$ Armour \& Gordon, supra note 12, at 64-76.

${ }^{151}$ For criticisms of Armour and Gordon's proposal, see Holger Spamann, Monetary Liability for Breach of the Duty of Care, 8 J. LEGAL ANALYSIS 337, 359 (2016) (hinting that Armour and Gordon's proposal may not be efficient in light of courts' inability to evaluate facts adequately: "the optimal liability [...] may be zero when court signals get too noisy, as might be the case for questions such as whether bank managers took excessive risks"); Saule T. Omarova, Bank Governance and Systemic Stability: The Golden Share Approach, 68 ALA. L. REV. 1029, 1039 (2017) (casting doubt on directors' ability to evaluate the systemic impact of a bank's risky behavior).

152 Armour and Gordon, supra note 12, at 53-56.

153 Armour and Gordon, supra note 12, at 64, 67-69.
} 
take the systemic relevance of their firm into account when making managerial decisions. On the contrary, they may actually lead to even riskier SIFI behavior.

At the most general level, liability rules commonly take two forms: harmbased liability and gain-based liability. While Armour and Gordon focus on gainbased liability, we explore both forms. In fact, harm-based rules are traditionally considered the first best solution. When courts can set the negligence standard at the optimal level and damages are calculated correctly, parties are then induced to take optimal care. ${ }^{154}$ It is only because, as we show, harm-based rules are unworkable in our setting that gain-based rules are resorted to. And it is in respect of the latter situation that a network-based tweak would be warranted.

A harm-based rule would require officers of SIFIs that negligently cause systemic harm to compensate victims for a sum that is equal to the systemic harm they have caused. There are at least two fundamental problems with this approach, however. First, the size of systemic harm is typically orders of magnitude larger than the assets of any director or manager. For instance, the bankruptcy process of Lehman Brothers alone caused direct losses of over $\$ 75$ billion, ${ }^{155}$ while between 2000 and 2008 the senior executives of Lehman had netted less than \$1bn in cash and stock. ${ }^{156}$ Although significant, this sum would not have been sufficient to cover the legal and professional fees associated with Lehman's failure. ${ }^{157}$ In short, there is a severe judgement-proof problem, and when injurers are judgement-proof they cannot be expected to adopt optimal care. ${ }^{158}$ Second, the fact that directors and managers are judgement-proof will result in problems of marginal deterrence. Given the enormous size of systemic harm, a harm-based liability rule would result in directors and managers having to give up all their assets whenever they negligently cause systemic harm. As a consequence, such a rule would crowd out projects that could cause smaller systemic harm in favor of projects that could cause larger systemic harm, ${ }^{159}$ provided that the latter have a higher payoff in the event that the project is successful.

154 COOTER \& ULEN, LAW AND ECONOMICS 208 (2012) (“Assuming perfect compensation and each legal standard equal to the efficient level of care, every form of negligence rule gives the injurer and victim incentives for efficient precautions").

${ }^{155}$ Sheila C. Bair, Chairman, Fed. Deposit Ins. Corp., We Must Resolve to End Too Big to Fail, 47th Annual Conference on Bank Structure and Competition (May 5, 2011), available at https://www.fdic.gov/news/news/speeches/chairman/spmay0511.html.

156 Lucian A., Bebchuk, Alma Cohen \& Holger Spamann, The Wages of Failure: Executive Compensation at Bear Stearns and Lehman 2000-2008, 27 YALE J. ON REG. 257, 259 (2010).

${ }^{157}$ Bair, supra note 154 ("More than two-and-a-half years after Lehman's failure, the process has cost over $\$ 1.2$ billion in legal and other professional fees").

158 SteVen Shavell, ECONOMIC ANALYSIS OF ACCIDENT LAW 167 (1987) (noting that the incentives to take care of judgement-proof injurers is suboptimal because "they will treat losses that they cause and that exceed their assets as imposing liabilities only equal to their assets").

159 David Friedman \& William Sjostrom, Hanged for a Sheep: The Economics of Marginal Deterrence, 22 J. LEGAL STUD. 345, 346 (1993) (noting that "[i]f we impose the same punishment however large the amount stolen, there is no incremental punishment for taking the tape deck as 
In short, a harm-based liability rule is theoretically unsound, given the gigantic judgment-proof and marginal deterrence problems that would be associated with it. This has an important corollary: in this context optimal deterrence cannot be achieved. Systemic harm is too large; thus, individual managers and directors cannot be induced to fully internalize the systemic harm that they create. In this vein, the only plausible goal for imposing personal liability on managers and directors of SIFIs is inducing them to account for the systemic relevance of their firm when deciding on a course of action.

Consistent with the idea that harm-based liability is unworkable in this context, Armour and Gordon suggest a gain-based liability rule for bank directors in the form of a claw back of the compensation received by managers of SIFIs over a certain time horizon $t$ (in months). ${ }^{160}$ Because optimal deterrence cannot be achieved, the choice of $t$ is a value judgement. A policymaker or a judge prioritizing systemic risk minimization will prefer a higher $t$, while a lower $t$ will be favored if the intention is to give SIFI managers incentives to undertake positive net-present-value projects as often as possible.

The expected liability $E l$ faced by the managers of a SIFI is then equal to:

$$
E l=t * x,
$$

where $x$ is the manager's monthly compensation. Because no measure of systemic relevance enters in (1), the expected liability faced by SIFI managers will not depend on the level of systemic relevance of their respective institution. Such a rule could therefore be desirable only under the implausible assumption that there is a group of financial institutions that have no systemic relevance $(S R=0)$, whereas all the others have the same systemic relevance $(S R=1)$.

The problem is that $S R$ is a continuous variable, not a binary one. For instance, one could measure $S R$ using DebtRank, and assign it any value between 0 and the economic value of the entire network (in dollars). Alternatively, one can normalize the DebtRank in a DebtRankScore (DRS), so that the value of the entire financial network corresponds to a DRS of 1. In this case, a SIFI's DRS would express the loss it would cause in the event of bankruptcy as a fraction of the value of the financial network. ${ }^{161}$ Similarly, one can create a Contagion Index Score (CIS) that equals one for the most systemically relevant institution and a fraction of one for other institutions. Because systemic relevance is a continuous variable and optimal deterrence cannot be achieved, the goal of the liability rule should then be

well as the television". The same logic applies here: harm-based liability rules would bankrupt any manager that causes significant systemic harm, and would therefore give managers no reason to differentiate between projects that can result in large or very large systemic harm).

${ }^{160}$ Armour \& Gordon, supra note 12 , at 67, 69.

${ }^{161}$ Financial institutions will then have a $0<D R S>1$, as most likely no institution will have $D S R=0$ or $D S R=1$. 
reformulated: managers of more systemically relevant firms should be induced to take more care for systemic harms than managers of less systemically relevant firms.

This goal cannot be reached under a non-network-sensitive liability rule. Indeed, the managers of two firms $\mathrm{A}$ and $\mathrm{B}$ with respectively, say, CIS $_{A}=0.2$ and $C I S_{B}=0.9$ would be facing the exact same liability. This outcome is problematic for at least three reasons. First, it defeats the very purpose of the rule, which is to induce SIFI managers to take the actual systemic relevance of their firm into account. Second, since there is an upside to being systemically important that increases in the level of systemic relevance of the SIFI (for instance the lower funding costs attached to being considered too-big-to-fail), ${ }^{162}$ an atomistic gainbased liability regime that is identical for all SIFIs reinforces the incentives to become as systemically important as possible. Third, a negligence-based liability rule for causing systemic harm introduces a significant departure from two fundamental principles of U.S. corporate law: the shareholder value maximization principle ${ }^{163}$ and the business judgement rule. ${ }^{164}$ Departing from these principles is not always justified, and certainly not always to the same extent.

As we have seen, ${ }^{165}$ the traditional shareholder-centric paradigm becomes problematic when shareholders and debtholders can rely on government intervention in cases when their firm is distressed. But, in the absence of the prospect of such an intervention, the shareholder value maximization principle and the business judgement rule serve important functions. The former principle ensures that managers have a clearly defined goal against which strategies and managerial decisions are assessed. ${ }^{166}$ And having this goal is widely believed to lead managers to adopt behavior that maximizes social welfare. ${ }^{167}$ The business

\footnotetext{
162 See supra note 147-149 and accompanying text.

163 See supra notes $138-141$ and accompanying text.

${ }^{164}$ For a formulation of the business judgement rule see e.g. Kamin v. American Express Co. 383 N.Y.S.2d 807 (Sup. Ct. 1976), aff d, 387 N.Y.S.2d 993 (App. Div. 1976) (discussing the issue of dividend payouts the court noted that "It is not enough to allege ... that the directors made an imprudent decision ... More than imprudence or mistaken judgement must be alleged.") and Gagliardi v. Tri-foods Int'l, Inc., 683 A.2d (1996) ("in the absence of facts showing self-dealing or improper motive, a corporate officer or director is not legally responsible to the corporation for losses that may be suffered as a result of a decision that an officer made or that directors authorized in good faith"). Therefore, "a decision constitutes a valid business judgement (and gives rise to no liability for ensuing loss) when it (1) is made by financially disinterested directors or officers (2) who have become duly informed before exercising judgement and (3) who exercise judgement in a good-faith effort to advance corporate interests" (ALLEN ET AL., supra note 138, at 243 (emphasis in the original)).

165 See supra Section III.A.

166 See e.g. Jensen, supra note 140, at 9, 13.

${ }^{167}$ See supra notes 138-140 and accompanying text, whereby also the important qualification that shareholder primacy does prevent companies from engaging in behavior that negatively affects third parties. Incidentally, though, there is no guarantee that relinquishing managers from the constraints
} 
judgement rule protects managers from liability for wrong business decisions and ensures that: $(i)$ managers' incentives are more aligned to the risk preferences of shareholders; and (ii) managers undertake the highest net-present-value projects. In fact, because managers have concentrated stakes in their firm, they are likely to be more risk-averse than diversified shareholders. ${ }^{168}$ Shielding them from liability reduces their risk-aversion, thus aligning their preferences to those of the shareholders.

Our key point is that deviations from standard principles of corporate law should be proportionate to the expected value of government intervention. When the expected value of such intervention is high, then a significant departure might be justified. On the other hand, when the expected value of the intervention is low, only marginal departures might be warranted. Referring back to SIFIs, for financial institutions that create more systemic risk a greater departure from the shareholder primacy norm and the business judgement rule may be justified, because the expected value of a government intervention relative to shareholders' investment is also greater. Instead, for firms that create less systemic risk, only a relatively small departure may be warranted. In our example, firms A and B should thus not be treated the same: they pose significantly different levels of risk and hence the expected value of government intervention is also different.

Armour and Gordon's proposal can be improved by connecting the liability faced by managers and directors to the systemic relevance of their firm. Let us modify the liability rule by introducing, for example, the CIS as an indicator of systemic relevance. ${ }^{169}$ The expected liability faced by managers can then be rewritten as

$$
E l=C I S * t * x,
$$

This correction is sufficient to ensure that the managers of firm B will face a higher liability than firm A's managers. This difference mirrors the different systemic relevance of the two institutions. To be clear, we reiterate that do not advocate for the CIS or for any specific coefficient of relevance. The choice of the coefficient depends on the specific characteristics of the network and on the

of shareholder primacy will per se curb negative externalities. What is sure is that such relaxation would help managers maximize their own welfare. See e.g. Stephen M. Bainbridge, In Defense of the Shareholder Wealth Maximization Norm: A Reply to Professor Green, 50 WASH. \& LEE L. REV. 1423 (1993).

168 ALLEN ET AL. supra note 138, at 244 ("Directors who risk liability for making unreasonable decisions - or even for failing to become reasonably informed or engaging in appropriate deliberation before acting - are likely to behave in a risk-averse manner that harms shareholders").

${ }^{169}$ Note that the operation of the principle we propose is the same regardless of the metric of systemic riskiness adopted. We propose to use the CIS here for the only reason that presently regulated entities might have problems gathering the information required to estimate the DRS. 
information available. For instance, the growing awareness that the structure of the financial network is essential for the regulation of financial markets might induce regulators to increase the reporting obligations of financial institutions, thus rendering viable the adoption of measures of systemic relevance that require more information. ${ }^{170}$

An important property of a network-sensitive liability rule is that it can be modified to account for structural properties of the financial network and for policymakers' preferences. For instance, (2) can be modified as follows

$$
E l=(\alpha * C I S * t * x)^{\beta},
$$

where $\alpha$ and $\beta$ are parameters set by the regulator. Although no optimal value of $\alpha$ and $\beta$ can be identified, the studies on the relationship between the interconnectedness and network resilience can offer some guidance on how to set these parameters. Let us recall that highly interconnected networks are resilient to small shocks, while loose ones are resilient to large shocks. ${ }^{171}$ Therefore, for financial institutions that are embedded in highly interconnected networks it might be desirable to set $\alpha<1$ and $\beta>1$. In this vein, the liability faced by managers of firms that can cause small systemic harm will be very small, but the liability will increase at a high rate when the CIS grows. Or, to put it differently, managers of high-CIS firms will face a much larger liability than managers of low-CIS firms. This reflects the fact that in highly interconnected networks high-CIS institutions can impose large losses, whereas the default of low-CIS institutions is generally well-absorbed. Conversely, weakly interconnected networks are sensitive to small shocks but are resilient to large shocks. In such cases, it could be advisable to set $\alpha>1$ and $\beta<1$. This ensures that the liability faced by low-CIS institutions is not too excessively smaller than the liability faced by high-CIS firms. This reflects the fact that in weakly interconnected networks even the default of low-CIS firms can have a significant effect, while the default of high-CIS firms will tend to have a local impact.

A simple numerical example can help clarify this point. Let us return to our firm A $\left(C I S_{A}=0.2\right)$ and firm B $\left(C I S_{B}=0.9\right)$. Let us also assume that the compensation of the two firms' CEOs of the is $\$ 1$ million per year and that $t=12$. In an atomistic framework the expected liability of both managers would be equal to $\$ 1$ million. Hence, their behavior will not be affected by the level of their firms' systemic relevance. Let us now switch to a network-sensitive regime (formula (6)) and start from the simplest scenario in which $\alpha=1$ and $\beta=1$. In this context, the expected liability of firm A's CEO is equal to $\$ 200,000$, whereas the expected

${ }^{170}$ See infra Part V.

${ }^{171}$ See supra notes $84-87$ and accompanying text. 
liability of firm B' CEO is equal to $\$ 900,000 .{ }^{172}$ Therefore, the expected liability of firm B's CEO will be more than four times that faced by firm A's CEO. This adequately reflects the fact that the two firms have very different systemic relevance.

Let us now hypothesize two additional scenarios. In the dense network (DN) scenario, firms A and B are embedded in a highly interconnected network, whereas in the loose network (LN) scenario they are embedded in a weakly interconnected network. ${ }^{173}$ We can assume that a small shock (firm A defaulting) will cause a harm equal to $h_{1}$ in the dense network scenario and to $h_{2}$ in the loose network scenario, with $h_{1}<h_{2}$. We can also assume that a large shock (firm B defaulting) will cause a harm equal to $H_{1}$ in the dense network scenario and to $H_{2}$ in the loose network scenario, with $H_{1}>H_{2}$. Unless one allows for values of $\alpha$ and $\beta$ that are different from one, the liability rule would not account for the fact that the same shock can have a different impact depending on the level of network interconnectedness. In other words, the liability faced by the CEOs of firms A and B will be the same in both scenarios, although one firm can be expected to cause more systemic harm in one scenario than the other. Table 2 illustrates how the regulator could set the values of $\alpha$ and $\beta$ to address this problem.

\begin{tabular}{|c|c|c|c|c|}
\hline Defaulting Firm & $\begin{array}{c}\text { Harm Caused } \\
\text { by the Shock }\end{array}$ & Relative Size of Harm & $\alpha$ and $\beta$ & Liability \\
\hline $\begin{array}{c}\text { A (DN } \\
\text { scenario) }\end{array}$ & $h_{1}$ & $\boldsymbol{h}_{\mathbf{1}}<h_{2}, H_{2}, H_{1}$ & $\alpha_{1}=0.04 ; \beta_{1}=1.5$ & 715,541 \\
\hline $\begin{array}{c}\text { B (DN } \\
\text { scenario) }\end{array}$ & $H_{1}$ & $h_{1}, h_{2}, H_{2}>\boldsymbol{H}_{1}$ & $\begin{array}{c}\alpha_{1}=0.04 ; \beta_{1} \\
=1.5\end{array}$ & $6,830,519$ \\
\hline $\begin{array}{c}\text { A (LN } \\
\text { scenario) }\end{array}$ & $h_{2}$ & $h_{1}<\boldsymbol{h}_{2}<H_{2}, H_{1}$ & $\alpha_{2}=5 ; \beta_{2}=1$ & $1,000,000$ \\
\hline $\begin{array}{c}\text { B (LN } \\
\text { scenario) }\end{array}$ & $H_{2}$ & $h_{1}, h_{2}<\boldsymbol{H}_{2}<H_{1}$ & $\alpha_{2}=5 ; \beta=1$ & $4,500,000$ \\
\hline
\end{tabular}

Table 2: Expected liability faced by the CEO of firms A and B in the cases of a highly interconnected network (Scenario I) and a weakly interconnected network (Scenario II) when $\alpha$ and $\beta$ are set by the regulator

As Table 2 illustrates, the liability outcomes now track the ordinal rank of expected systemic harm caused in the different scenarios. The ordering of the harms according to their size is in fact:

${ }^{172}$ The calculation is based on (6). Since $\alpha=1$ and $\beta=1$, the liability of A's CEO is equal to $C I S_{A} * t * x=200,000$, and the liability of B's CEO is equal to $C I S_{B} * t * x=900,000$.

${ }^{173}$ In principle, changing the structure of the network will also change the CIS. However, to keep the exposition as simple as possible we leave this effect aside. 


$$
h_{1}<h_{2}<H_{2}<H_{1}
$$

which mirrors the ranking of expected liability. Thus, network theory tools allow the regulator to fine-tune the liability rule so that behavior that can result in larger systemic harm is associated with higher expected liability, even when the precise value of the systemic harm that is attributable to the conduct of a manager cannot be estimated. All that is required is some information about the network in which SIFIs are embedded.

Two objections are anticipated. ${ }^{174}$ First, it could be argued that the values of $\alpha$ and $\beta$ chosen in the example are highly discretionary, if not arbitrary. This point is conceded. However, the values of $\alpha$ and $\beta$ are arbitrary under any liability rule when optimal deterrence cannot be achieved. For instance, the non-network version of this rule can be expressed in the form of equation (3), with $\alpha=\frac{1}{C I S}$ and $\beta=1$. These values are just as arbitrary as any other but have the additional disadvantage that they lack the property of exposing managers that can cause more systemic harm to higher liability. Moreover, as the network tools used by economists become more sophisticated, it might become possible to ground the values of $\alpha$ and $\beta$ on more objective factors.

A second possible objection is that SIFI managers and directors are not aware of the systemic relevance of their firm and therefore cannot plan their behavior accordingly. The answer to this objection depends on the indicator used and on the amount of information available to the managers. If the CIS is used, then a SIFI's directors and managers will be able to calculate its systemic relevance at any point in time. If an indicator such as the DebtRank is adopted, however, the estimation of the systemic relevance of a financial institution ought to be made by the regulator and communicated to the relevant firms (and the public). Depending on the reporting requirements, this measure can be calculated more or less accurately (and frequently). Yet, no matter how imperfect these measures of systemic relevance are, they are certainly more accurate than assigning the same systemic relevance to all SIFIs.

\footnotetext{
${ }^{174}$ Another two objections to network-sensitive rules more generally are discussed in Part IV. Additionally, one might be concerned that this rule leads to too much (or too little) liability compared to the one advocated by Armour and Gordon. If that is a concern, then it can be solved by setting $\alpha=\frac{1}{\overline{C I S}}$ and $\beta=1$, where $\overline{C I S}$ is the average CIS of the SIFIs considered, which would make the average level of deterrence of our rule identical to that of Armour and Gordon.
} 


\section{Managerial Compensation}

In parallel with proposals to tighten liability rules, ${ }^{175}$ the idea of regulating the compensation of SIFI executives to reduce their incentives to take excessive (systemic) risks has been explored.

In particular, Lucian Bebchuk and Holger Spamann have argued that, instead of being tied only to the value of common shares, bank executives' compensation should be tied to a broader basket of securities that includes bonds and preferred stocks. ${ }^{176}$ The underlying logic is that debtholders do not enjoy an unlimited upside from the successful risky bets of a bank but suffer significant losses in case where a given risk materializes, hence making them more risk-averse than equity holders. Thus, requiring SIFI executives to receive part of their compensation in the form of debt should reduce their incentives to take excessive risk. $^{177}$

In the pursuit of the very same goal of reducing "excessive risk taking," the E.U. has intervened even more radically on the structure of bank executives' compensation. In particular, the Fourth Capital Requirements Directive (hereinafter, the CRD IV) caps variable compensation, including stock-based compensation, to 100 percent of the fixed salary, or, subject to shareholder approval, 200 percent thereof. ${ }^{179}$ The rationale here is that a larger variable component of compensation increases managers' incentives to engage in risky projects.

\footnotetext{
${ }^{175}$ See supra, Section III.B.

${ }^{176} \mathrm{Id}$. at 253 . Building on the same framework, Frederick Tung has similarly suggested that compensation of banks executives should in part be composed of their bank's publicly traded subordinated debt securities. Tung, supra note 17, at 1207. Sanjai Bhagat and Roberta Romano take a different path to prevent excessive risk-taking on the part of banks' executives. Their idea is to compensate executives with restricted stocks and restricted stock options that cannot be sold (or the option cannot be exercised) for a period of at least two to four years after the executive leaves the office: by focusing executives' attention on the mid-long term, this solution would prevent executives from taking excessive risks to favor short-term share price increases. Bhagat \& Romano, supra note supra note 17, at 361 (while they develop their proposal for firms receiving government financial assistance, they also argue that it can be extended to any financial firm that benefits from deposit insurance). While here we keep our focus on Bebchuk and Spamann's proposal, tweaks similar to the ones we suggest below could be applied to both Tung's and Bhagat and Romano's proposals.

${ }^{177}$ Notably, while their main concern is not systemic risk, they recognize that bondholders do not monitor banks because they can expect a bail-out (Bebchuk \& Spamann supra note 18, at 266-67). As the too-big-to-fail problem is rooted in the idea that the default of a large financial institution firm might have systemic consequences, their proposal is intimately related with systemic risk.

${ }^{178}$ Council Directive 2013/36 of the European Parliament and of the Council of 26 June 2013 on Access to the Activity of Credit Institutions and the Prudential Supervision of Credit Institutions and Investment Firms, 2013 O.J. (L 176) 338, 345.

${ }^{179} \mathrm{Id}$. at 387 (Article 94(1)(g)). Member States may set an even lower variable-to-fixed ratio. Id.
} 
While both prescriptions would mitigate the tendency of managers to take excessive risks, they (would) come at a cost: each of them can be criticized for different reasons, ${ }^{180}$ but both, by imposing deviations from the shareholder value maximization principle, thwart managers' incentives to engage in valuemaximizing projects.

As we do not advocate for or against these prescriptions, we remain agnostic as to whether their benefits outweigh their costs. We claim, however, that a better balance between the costs and benefits associated with them could be reached by factoring in network effects.

The compensation of a SIFI top executive ${ }^{181}$ is mainly the sum of a cash and equity-based component: ${ }^{182}$

$$
P a y=C a+E q
$$

where Pay is the overall compensation, $\mathrm{Ca}$ is the cash received by the executive and $E q$ is the equity-based compensation. Bebchuk and Spamann's proposal would introduce the following constraint:

$$
D e \geq \gamma *(E q+C a)
$$

where $D e$ is the value of the debt-based compensation and $\gamma$ is a parameter defined by the regulator. Bebchuk and Spamann do not attempt to identify the value that should be assigned to $\gamma$. to be operationalized, however, their proposal requires the regulator to assign a numerical value to such a parameter. In other words, the regulator must specify the minimum fraction of an executive's compensation that should comprise debt instruments.

${ }^{180}$ See Jeffrey N. Gordon, Corporate Governance and Executive Compensation in Financial Firms: The Case for Convertible Equity-Based Pay, Colum. Bus. L. Rev. 834, 851-853 (2012) (criticizing Bebchuk and Spamann's proposal); Kevin J. Murphy, Regulating Banking Bonuses in the European Union: A Case Study in Unintended Consequences, 19 EUR. FIN. MANAGEMENT 631 (providing a devastating critique of the E.U. rules); Guido Ferrarini, CRD IV and the Mandatory Structure of Bankers' Pay 34-8, ECGI - Law Working Paper No. 289/2015, https://ssrn.com/abstract=2593757 (same); see also Id. at 37 for the criticism that

[the] cap reflects a 'one-size-fits all' approach which is clearly too rigid, for different types of credit institutions present different levels of risk exposure, so that an incentive structure which is appropriate for one firm is not necessarily suited to another. Moreover, the EU bonus-cap applies to all credit institutions, without regard to their size and therefore to systemic risk considerations.

181 The compensation schemes of lower rank executives are often different from that of top executives. The analysis presented here only focuses on the latter. We remark, however, that the discussion presented in this Section can easily be extended to lower rank executives.

182 See Tung supra note 17 , at 1227. 
Holding Pay constant, higher values of $\gamma$ will result in a higher $D e /(E q+$ $\mathrm{Ca}$ ) ratio. Hence, the executives will have less incentives to take risk when $\gamma$ is higher. However, as explained above, a high $D e /(E q+C a)$ ratio also comes at a cost, and that cost might not be worth bearing for all SIFIs to the same extent.

Let us go back to our previous example where two firms, A and B, have $C I S_{A}=0.2$ and $C I S_{B}=0.9$, respectively. As noticed in Section III.B, those firms' contributions to systemic risk varies significantly. Hence, lower (higher) values of $D e /(E q+C a)$ should apply to firm A (B). One possible way to frame the problem is as follows. Shareholders and managers of both firm A and firm B have incentives to engage in excessive risk, whereas debtholders of both firms prefer conservative strategies. However, erring on the side of excessive risk has more serious consequences in the case of firm B than of firm A. At the same time, the debtholders and the shareholders of firm A will monitor SIFI executives more carefully because the expected value of government aid for a firm with limited systemic relevance is smaller. ${ }^{183}$ To differentiate along the systemic risk dimension, the constraint introduced in equation (6) can be modified as follows

$$
D e \geq C I S * \gamma *(E q+C a) .
$$

In this vein, the proportion of pay granted in debt securities will be higher when the systemic relevance of the firm is high, whereas the cash and equity components of the compensation package will be higher when the systemic relevance of the firm is low. ${ }^{184}$

A similar approach can be applied to improve on the constraint imposed by the CRD IV on the compensation of bank executives. Executive compensation can also be described as:

$$
\text { Pay }=\text { Fix }+ \text { Var }
$$

where Fix denotes the fixed salary and Var captures the variable part of the compensation. The CRD IV imposes the following constraint:

$$
F i x \geq \zeta * \operatorname{Var}
$$

where $\zeta=1$ without shareholders' approval, and $\zeta=1 / 2$ with shareholders' approval. For a given value of Fix higher values of $\zeta$ will give executives less incentives to engage in risky behavior but also less incentives to maximize the value

\footnotetext{
${ }^{183}$ See supra note $147-149$ and accompanying text.

${ }^{184}$ Parameters similar to $\alpha$ and $\beta$ discussed in Section III.B can be introduced to account for features of the network like interconnectedness.
} 
of their firm. Here again, the value of $\zeta$ should depend on the degree of systemic risk posed by the SIFI. Thus, (9) can be modified as follows

$$
F i x \geq C I S * \zeta * V a r
$$

To be sure, compensation schemes of this kind do not induce executives to consider the systemic harm that extends beyond shareholders and debtholders. ${ }^{185}$ After all, the compensation of managers and directors is only affected by the debt and equity of their own firm, and not by the systemic consequences of their actions. To address this limitation, Bebchuk and Spamann propose lowering executive compensation to account for any payment made by the Government to support the bank. ${ }^{186}$ In practical terms, this is the liability rule described in Section III.B kicking in. In other words, the proposals of Bebchuk and Spamann and of Armour and Gordon suggest virtually the same solution to induce managers to internalize the systemic harm that they cause (in the case of Bebchuk and Spamann, the systemic harm is proxied by government payments). Combining the network-sensitive stick (liability) with the network-sensitive carrot (compensation) allows policymakers to induce SIFI executives to internalize a larger portion of systemic harm, while calibrating their intervention for the systemic relevance - as measured by network theory indicators - of the SIFI.

\section{Failing SIFI Shareholder Rights in Shadow Resolutions}

Yair Listokin and Inho Mun argue that corporate law can play a greater role than it currently does in mitigating systemic risk. ${ }^{187}$ In particular, they note that an important tool that is routinely used to mitigate the negative consequences of a financial crisis is "regulation by deal" (or shadow resolution) by which a solid financial firm acquires a defaulting SIFI under pressure from and/or with the financial support of the government. ${ }^{188}$ While regulation by deal ensures that the

\footnotetext{
185 Bebchuk \& Spamann, supra note 18, at 284 (noting that even tying executives' compensation to a broader basket of securities would not lead them to "internalize and take into account fully the adverse consequences that risk-taking might have for the interests of the government as guarantor of deposits").

${ }^{186}$ In particular, Bebchuk and Spamann supra note 18, at 284, propose to subtract (or claw back) from executives' compensation "any payments made by the government to the bank's depositors, as well as other payments made by the government in support of the bank, during the period ending at the specified time."

${ }^{187}$ Listokin and Mun, supra note 22, at 4.

${ }^{188}$ Listokin \& Mun supra note 22, at 4-5. The term shadow resolution is used by Luca Enriques \& Gerard Hertig, Shadow Resolutions As a No-No in a Sound Banking Union, in FINANCIAL REgulation. A Transatlantic PERSPECTIVE 150 passim (Ester Faia et al eds., 2015).
} 
negative externalities associated with the default of the target SIFI are prevented, it also allows the shareholders of the defaulting firm to hold the economy hostage. In fact, knowing that by opposing the merger they can impose a significant externality on the economy, the shareholders of the defaulting SIFI will attempt to extract rents, in the form of a higher price for their shares, from the acquirer. ${ }^{189}$ Ultimately, whenever the government provides financial assistance for the deal, the cost of this hold-up problem is, partially or fully, borne by taxpayers.

To prevent this, Listokin and Mun contend that target SIFI shareholders should have no vote on the merger and their appraisal rights should be tweaked as well. ${ }^{190}$ Target SIFI shareholders would then have no way to reject a merger during a time of economic distress, thereby losing the ability to extract money from taxpayers. ${ }^{191}$ In addition, their appraisal rights would be attenuated. If that were not the case, the appraisal remedy would make shareholders whole, which, ex ante, would give them no incentive to monitor their managers; as a consequence, managers and directors might be induced to act in a reckless way. ${ }^{192}$

That is why Listokin and Mun suggest awarding shareholders only a fraction (more precisely, half) of the appraisal value as defined according to the general criteria. ${ }^{193}$ In other words, if $V$ is the award received by the shareholders of the target SIFI and $A$ is the appraisal value, according to Listokin and Mun's proposal, the target SIFI shareholders would receive

$$
V=\frac{A}{2}
$$

Because achieving optimal deterrence in the context of systemic risk is impossible,${ }^{194}$ one half would seem to be no better or worse than one-quarter or three-fifths. But this does not mean that such a policy should ignore the level of systemic relevance of the target SIFI. Let us recall that lower values of $V$ reduce the incentives of managers to engage in reckless behavior, while inducing shareholders to monitor them. At the same time, however, lower values of $V$ increase the cost of capital for SIFIs and undercompensate shareholders for the loss of their voting rights. This is extremely important for a SIFI which is in the vicinity of insolvency but still viable as an independent business: a new issue of shares to

\footnotetext{
${ }^{189} I d$. at 16.

${ }^{190} I d$. at 27-30. A second proposal by Listokin and Mun (id., at 30-32), that is, to tweak fiduciary duties of target SIFIs' directors and officers to allow them the discretion to say yes to the shadow resolution transaction is not addressed here.

191 Id. at 28 .

192 Id. at 29.

${ }^{193}$ Ibid. (as an alternative, Listokin \& Mun propose that courts use "a discount rate [to determine the appraisal price] that is the prime rate plus a penalty premium". The tweak we propose in the text could similarly be used to improve this alternative proposal by making it network-sensitive).

194 See supra notes 155-159 and accompanying text.
} 
recapitalize the company will be much harder to complete with Listokin and Mun's rule in place. Yet, the recapitalization of an ailing SIFI should be preferable to merging it with a sounder SIFI, for at least three reasons. First, the merger will create an even larger entity, which may wield even greater market (and political) power, making it likelier that, should it be insolvent, the Government will bail it out. Second, regulation by deal has a dark side: supervisors may persuade the acquirer to save the ailing SIFI not just through explicit financial subsidies (e.g. guarantees) but also by promising a benevolent supervisory stance after the merger. ${ }^{195}$ Relatedly, and third, this practice also distorts competition because "[b]anks that are closer to regulators or have superior political contacts are likely to benefit from various shadow competitive advantages." 196

Therefore, this rule entails a trade-off and the adequate resolution of this trade-off, once again, depends on the SIFI's systemic relevance. ${ }^{197}$ For SIFIs with high systemic relevance, it is important to ensure that shareholders have strong incentives to monitor and, correspondingly, that managers and directors have strong incentives not to undertake exceedingly risky projects. In this vein, for these firms it is desirable to set a low value of $V$. To the contrary, SIFIs with lower systemic relevance are liable to impose smaller losses on society. Thus, for such SIFIs a higher appraisal value can be awarded without endangering the economy.

Integrating Listokin and Mun's proposal with a network-sensitive component would make this calibration possible. For that purpose, it would be sufficient to modify equation (11) as follows

$$
V=A(1-D R S)
$$

This adjustment ensures that shareholders of firms with a high DRS will receive less than those of firms with a low DRS. There is a strong reason for preferring DRS over CIS in this context. By construction, the CIS of the most systemically relevant firm will be equal to 1 , and it is possible that at least some of the other most interconnected institutions will have a similar score. This implies that the shareholders of one SIFI will receive no compensation for being stripped of their voting rights, and shareholders of other large SIFIs will receive almost nothing. This appears to be an undesirable outcome.

By definition, however, a SIFI cannot have $D R S=0$ (otherwise it would not be a SIFI), and it is unlikely that any SIFI has a DRS equal to 1 . Therefore, the effect of this amended rule is that shareholders of more systemically relevant firms

\footnotetext{
195 See Enriques \& Hertig, supra note 188, at 153.

${ }^{196} I d$.

${ }^{197}$ Once again, we do not advocate in favor or against this proposal per se. As elsewhere in this Part, our point is that, if the benefits of regulation by deal exceed its costs, network effects should be included in the equation.
} 
will receive less, and hence have greater incentives to monitor managers. In turn, this will reduce the likelihood of the latter engaging in reckless behavior.

\section{E. Bumpy Atomistic Rules Versus Smooth Network-Sensitive Ones}

An important property of the network-sensitive rules we advocate here is that they allow for the smoothening of "bumpy" rules. A rule is bumpy when small differences in behavior result in drastically different legal outcomes. ${ }^{198}$ For example, "a slightly incautious driver who causes an accident may owe millions of dollars. Had he been a bit more cautious and still been in an accident, he'd owe nothing." 199 The liability regime proposed by Armour and Gordon is bumpy on two dimensions. On the one hand, like in the case of the driver, a slightly negligent director would face an expected liability of millions of dollars, while a slightly more cautious director would not be liable. On the other hand, a slightly negligent director of a firm that is just above the threshold of systemic relevance would face a high expected liability, whereas a slightly negligent director of a firm that is just below that threshold would be exempt. A recent article by Christina Parajon Skinner describes at great length the costs that large financial institutions incur to avoid the "bumpy" SIFI label and the associated regulatory burdens. ${ }^{200}$ Such costs range from investing resources to lobby the competent authorities, ${ }^{201}$ to restructuring their business model or recapitalizing. ${ }^{202}$ Rules that are bumpy on more than one dimension would exacerbate this problem by further strengthening the incentives to avoid the SIFI label.

The network-sensitive rule that we propose smoothens Armour and Gordon's rule on the liability regime dimension, because the expected liability faced by directors and executives would become a continuous function of the systemic relevance of their firm. In other words, an institution's directors and executives will only be able to reduce their expected liability by reducing in a commensurate way the systemic risk that their institution poses.

Similarly, Listokin and Mun's proposed solution for shadow resolutions is bumpy on three dimensions: ${ }^{203}$ ( $i$ ) either firms are systemically important or not; (ii) either shareholders are allowed to vote or not; and (iii) either shareholders receive a fraction of the appraisal value - that is equal across all SIFIs - or they

\footnotetext{
${ }^{198}$ See Adam J. Kolber, Smooth and Bumpy Laws, 102 CAL. L. REv. 655, 657 (2014).

${ }^{199} \mathrm{Id}$.

${ }^{200}$ Christina Parajon Skinner, Regulating Nonbanks: A Plan for SIFI Lite, 105 GEO. L. J. 1379, 1392-96 (2017).

${ }^{201} I d$. at $1398-99$.

${ }^{202} I d .1399-1400$.

${ }^{203}$ Incidentally, we note that it is impossible to tell whether Bebchuk and Spamann's proposal is bumpy, because they do not specify how to determine the debt/equity ratio that should constrain executive pay.
} 
receive the full value. By its own design, dimension (ii) cannot be smoothened, because the law has to make a discrete choice between allowing shareholders to vote or not. ${ }^{204}$ On the contrary, dimensions (i) and (iii) can and should be smoothened. By treating slightly important SIFIs and really important SIFIs in the same way - that is, by awarding their shareholders the same fraction of the appraisal value - one penalizes the former and benefits the latter. In fact, the latter enjoy larger implicit subsidies in cases of default and more significant economies of scale, while the former would be asked to bear the same regulatory burdens despite contributing less to systemic risk. The network-sensitive tweak we have suggested allows the policy to connect the fraction of appraisal awarded to the shareholders to the systemic relevance of their firm, thus correcting the distortion.

Finally, smooth rules also have an important advantage in terms of fairness. Bumpy rules treat similar cases in drastically different ways, which is, if not morally troublesome, politically objectionable. ${ }^{205}$ Instead, smooth rules enable policymakers to treat similar cases similarly, thus calibrating the legal burden imposed by the regulation to the relevant features of the addressed phenomena.

\section{Possible Counterarguments to NeTWORK-SENSITIVE REGULATIONS}

Network-sensitive regulations allow policymakers to tailor regulations to the specific characteristics of the financial network that individual financial institutions and their agents belong to. However, it could be argued that they introduce an element of complexity to the regulatory framework while not improving much on traditional atomistic regulations. On the one hand, the differences between institutions might not be that relevant, so a binary distinction between SIFIs and non-SIFIs might be a good enough heuristic. On the other hand, size could be an adequate approximation of systemic relevance, and there would be no need for the added complexity we have advocated for in the previous part to account for differences in interconnectedness between financial institutions. In addition, one may fear that any network-sensitive parameter, when used to regulate market players' behavior, will be subject to Goodhart's law ${ }^{206}$ and fail to properly address

\footnotetext{
${ }^{204}$ Kolber, supra note 198 , at 658 :

Sometimes, we have to select a discrete outcome. In such cases, the law has bumpy needs. For example, the Constitution mandates that the president be at least thirty-five years old. Although nothing magical happens precisely when a person turns thirty-five, there may be no practical way to smooth the relationship between maturity and eligibility for the presidency-you cannot be a little bit president.

In a similar vein, shareholders cannot cast "a little bit" of a vote.

${ }^{205}$ Kolber, supra note 198, at 684-85.

${ }^{206}$ Goodhart's Law (named after British Economist Charles Goodhart) states "that any indicator may become useless once it is used for regulatory purposes." Ester Faia \& Isabel Schnabel, The
} 
systemic risk as an outcome of market players' reaction and adaptation to the parameter to minimize its negative impact upon them.

First, the incremental changes proposed in this article are easy to implement, as calculating measures of systemic relevance, such as the Contagion Index, appears to be straightforward. In fact, Glasserman and Young calculate the Contagion Index of some of the most relevant European anks without having access to any private dataset. ${ }^{207}$ Second, a large body of research shows that adopting a binary measure of systemic risk yields no good approximation. ${ }^{208}$ For instance, in a widely cited paper Cont, Moussa and Santos measure the systemic relevance of Brazilian financial institutions between 2007 and 2008. ${ }^{209}$ To do so, they build a contagion index that captures the expected losses (in billions of Brazilian Reals (BRL)) that would result from the default of a given institution. Table 3 depicts the systemic relevance of the most contagious nodes.

\begin{tabular}{|c|c|}
\hline Rank & Contagion Index (BRL billion) \\
\hline 1 & 3.48 \\
\hline 2 & 3.40 \\
\hline 3 & 2.09 \\
\hline 4 & 1.78 \\
\hline 5 & 1.45 \\
\hline
\end{tabular}

\section{Table 3: The five most contagious nodes in Brazil in June 2007. ${ }^{210}$}

As table 3 shows, a default of the most contagious node can cause losses that are 2.4 times larger than the losses that would be caused by the default of the

Road from Micro-Prudential to Macro-Prudential Regulation, in FINANCIAL REGULATION, supra note $195,3,12$.

${ }^{207}$ Glasserman and Young, supra note 74, at 395-398.

${ }^{208}$ Serafin Martinez-Jaramillo et al., An Empirical Study of the Mexican Banking System's Network and Its Implications for Systemic Risk, 40 J. ECON. DyNAMICS \& CONTROL 242 (2014); Kimmo Soramaki et al., The Topology of Interbank Payment Flows, 379 PHYSICA A: STATISTICAL MECHANICS AND ITS APPLICATIONS 317 (2007).

${ }^{209}$ Rama Cont, Amal Moussa \& Edson Santos, Network Structure and Systemic Risk in Banking Systems, in HANDBOOK ON SYSTEMIC RISK 327 passim (Jean-Pierre Fouque \& Joseph A. Langsam eds., 2013).

210 The data is from id., at 358 . 
fifth most contagious node. Thus, even among the most contagious nodes there are very significant differences. Critically, although the authors find that institutions with larger interbank exposures tend to be more contagious, they also find that an institution's position within the network plays a critical role ${ }^{211}$ - thus strengthening the case for network-sensitive, rather than atomistic regulation.

A more "graphical" proof that systemic relevance cannot be reduced to a binary variable is offered by Poledna et al. ${ }^{212}$ In their study, they analyze the Mexican banking system using a multi-layered network that accounts for four layers of interconnections: deposits and loans (DL), security cross-holdings (secu), derivatives (deri) and foreign exchange $(\mathrm{FX}){ }^{213}$ Then, they calculate the DebtRank of Mexican banks. Their findings are reported in Fig. 2, which vividly illustrates that it is impossible to group financial institutions into two categories (SIFIs and non-SIFIs) without losing a significant amount of information on the systemic relevance of each node. ${ }^{214}$

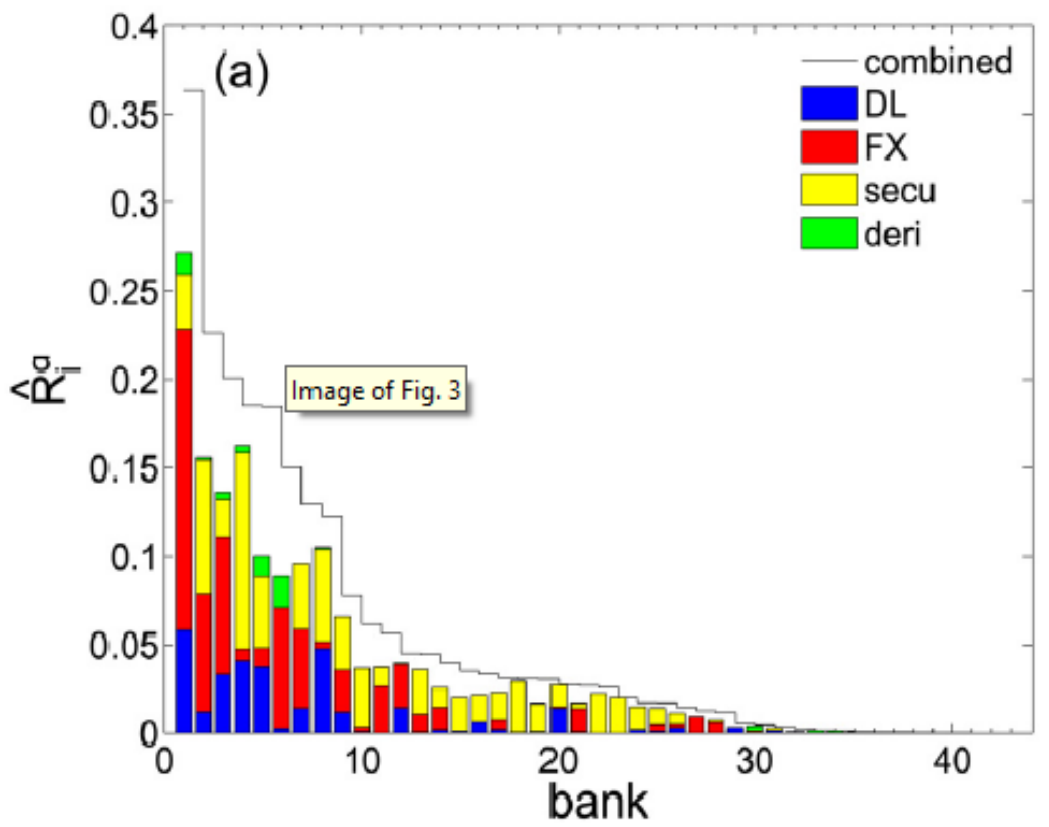

Figure 2: The normalized DebtRank for each bank decomposed for the four layers considered. ${ }^{215}$

${ }^{211} I d$. (finding that the resilience of an institution's counterparties matters: an institution with relatively weak counterparties may be more contagious than an institution with a similar number of more resilient counterparties that are better able to manage potential losses).

${ }^{212}$ Sebastian Poledna et al., The Multi-layer Network Nature of Systemic Risk and Its Implications for the Costs of Financial Crises, 20 J. FIN. STABILITY 70 (2015).

${ }^{213} I d$. at 73-76.

${ }^{214}$ Similar findings are reported also in Thurner \& Poledna, supra note 71.

215 Poledna et al., supra note 212, at 76. 
Most importantly, an approximation is only as good as the cost-savings that it allows. Because amending the policy proposals discussed in this article so that they incorporate the insights of network theory appears to have very low direct costs, network rules would represent an improvement even if they were only marginally more accurate.

Third, a large body of literature shows that the size of a financial institution is not the only determinant of its systemic relevance. ${ }^{216}$ Analyzing three samples of banks (global, EU and euro area), Alessandri et al. find that the systemic relevance of an organization is more related to its complexity than its size. ${ }^{217}$ Moreover, Galbiati et al. note that "network drivers are not necessarily the largest institutions in a system: as in the works of a clock, a small cog can move a larger one and eventually the whole machine." ${ }^{218}$ To put it differently, small nodes might play a key role in a network. Strong proof that systemic relevance and size are not coterminous is offered by Battiston et al., whose data show that some banks have a very high DebtRank despite their relatively small size (e.g. Bank of America (BOA) and JP Morgan (JPM)), whereas others have a relatively small DebtRank despite being very large (e.g. UBS) (Fig. 3). ${ }^{219}$

\footnotetext{
${ }^{216}$ Lumsdaine et al., supra note 78, at 1 ("while size-based thresholds are appealing from a regulatory perspective [...], they are overly simplistic in the presumption that risk can be evaluated via a single value"); Cont et al., supra note 209, at 31 (noting that "factors other than size contribute to [banks'] systemic importance"); Martinez-Jaramillo et al., supra note 208, at 256 (noting that centrality measures "go beyond size and, in some cases, are not correlated or even negatively correlated with the size of an institution").

${ }^{217}$ Piergiorgio Alessandri, Sergio Masciantonio \& Andrea Zaghini, Tracking Banks' Systemic Importance Before and after the Crisis, 18 INT'L FIN. 157, 171 (2015).

${ }^{218}$ Galbiati et al. supra note 60, at 127.

${ }^{219}$ Battiston et al., supra note 46 , at 4.
} 


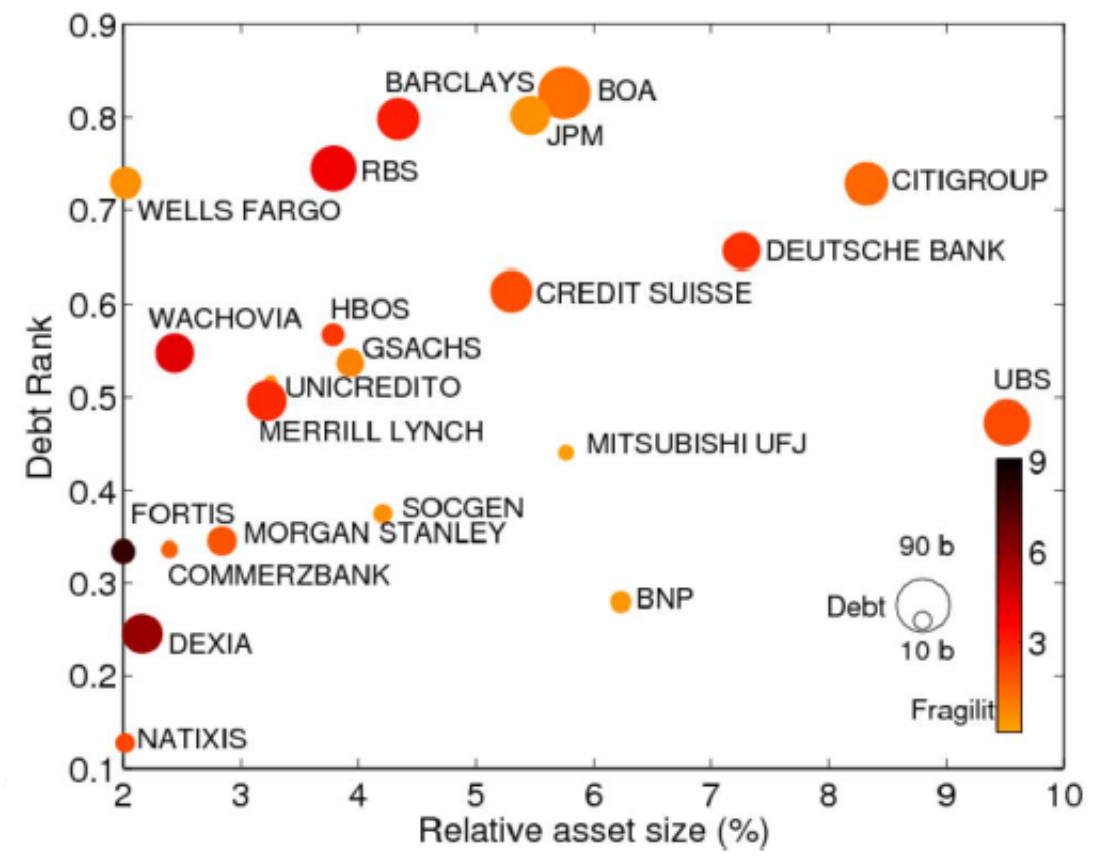

Figure 3: The relationship between DebtRank and the relative asset size of some of the most relevant financial institutions at the peak of the financial crisis. ${ }^{220}$

One last concern may be that financial institutions could game the indicators. For example, market players could learn how to lower their DebtRank without actually reducing the level of risk that they impose on the economy. Naturally, the better the indicators used, the less serious the concern, though. Nevertheless, since perfect indicators cannot be devised, there will always be some room for gaming by market players. It would therefore be important that regulators choose a suitable combination of indicators to minimize this problem.

At the same time, the room for gaming may not be that wide. On the one hand, to arbitrage network-sensitive indicators, a SIFI would have to fundamentally change whom it does business with, because those indicators are based mostly - if not exclusively - on contractual relations. Thus, the costs that would have to be borne to affect an indicator are likely to be significant. On the other hand, the proposed indicators are smooth, and therefore the possible gains from gaming them are relatively limited because they are proportional to the reduction in the indicators achieved via gaming. Instead, the gaming problem might be much more severe with bumpy rules, when a marginal reduction in the value of an indicator

${ }^{220}$ Data are from Battiston et al., supra note 46, at 4 . A copy of the Creative Commons License under which this figure is licensed is available at http://creativecommons.org/licenses/by-nc-sa/3.0/. 
allows a SIFI to locate itself just below the threshold and thereby obtain disproportionately large benefits.

\section{Research Agenda: The Case of Disclosure and RePorting OBLIGATIONS}

The growing awareness that interconnections among financial institutions is a key determinant of systemic risk, combined with the increasing sophistication of network models, suggests that network theory has great promise for financial regulation. The more refined network theory becomes, the better its ability to answer questions that atomistic approaches cannot even begin to ask. However, any paradigm shift has profound ramifications that have to be investigated in order to manage the transition and minimize frictions among different legal domains. Future research should attempt to ease this transition by investigating how a more extensive use of network tools in taming systemic risk can interact with the existing laws.

One obvious set of rules that will be affected by this shift are disclosure and reporting requirements for financial institutions. To implement network-sensitive regulation, regulators need to have a clear view of the financial network. That, in turn, requires detailed information on the precise linkages between financial institutions. The then Vice-Chair of the Federal Reserve, Janet Yellen, argued that, "[w]ithout such comprehensive and detailed data, it is simply not possible to understand how stress in one part of the network may spread and affect the entire system." ${ }^{221}$ Following the financial crisis, this understanding, as well as the realization that data had been insufficiently available prior to the crisis, dawned on policymakers. $^{222}$ In the Dodd-Frank Act, various actions were taken to enhance data collection efforts. Institutionally, perhaps the most important innovation was the establishment of the OFR. ${ }^{223}$ This new and independent bureau, embedded in the U.S. Treasury Department, is responsible for the collection and standardization of financial data gathered across the Government, and for the development of riskmanagement and monitoring tools for the financial system as a whole. ${ }^{224}$ The OFR supplies this data and provides analytical support to the FSOC, which has among its tasks the identification of risks to financial stability that could arise from the material financial distress or failure, or ongoing activities, of financial

\footnotetext{
221 Yellen, supra note 4.

${ }^{222}$ International Monetary Fund, supra note 45, at 73 (noting that filling the "information gaps" on systemic linkages "would require improved data collection procedures and impose additional demands on financial institutions").

${ }^{223}$ Dodd-Frank Act, $\S 152,12$ U.S.C. $\S 5342$ (2017).

${ }^{224}$ Dodd-Frank Act, $\S 153,12$ U.S.C. $§ 5343$ (2017).
} 
institutions. ${ }^{225}$ As part of this responsibility, the FSOC plays a key role in the administration of network-sensitive regulations. ${ }^{226}$ In addition to setting up these new bodies, the Dodd-Frank Act also established new and far-reaching mandates to gather extensive financial data about the financial network. ${ }^{227}$ Perhaps the most striking of such mandates is the requirement under Title VII that all credit default swaps involving U.S. entities be reported to Swap Data Repositories (SDRs) regulated by the Commodity Futures Trading Commission or the Securities and Exchange Commission. ${ }^{228}$ The data in these SDRs can then be used to reconstruct the financial network. ${ }^{229}$

But it is not only reporting requirements that are important. Network theory reveals that the risk associated with a transaction depends not only on the characteristics of the two institutions involved but also on the connections of the two parties with other financial institutions, and ultimately on the structure of the financial network. ${ }^{230}$ Market participants might have information on the characteristics and solvability of their counterparts but can rarely assess the reliability of the networks of agents with which each of their counterparts is interacting. ${ }^{231}$ However, without adequate information on the structure of the

${ }^{225}$ Dodd-Frank Act, $\S 112,12$ U.S.C. $\$ 5322$ (2017).

${ }^{226}$ Dodd-Frank Act, $\S 112(a)(2)(I), 12$ U.S.C $§ 5322(a)(2)(I)$ (2017) (specific tasks of the FSOC include "making recommendations to the Board [of Governors of the Federal Reserve] concerning the establishment of heightened prudential standards for risk-based capital, leverage, liquidity, contingent capital, and overall risk management for nonbank financial companies and large, interconnected bank holding companies supervised by the Board").

${ }^{227}$ See e.g. Dodd-Frank Act, $\S 153,12$ U.S.C. $\S 5343($ a) (2017) (a complete review of the data gathering mandates is beyond the scope of this article).

${ }^{228}$ Dodd-Frank Act, $\S \$ 727$ (amending the Commodity Exchange Act, 7 U.S.C. 2(a)), 728 (amending the Commodity Exchange Act, 7 U.S.C. 24a), 17 C.F.R. § 45 (2018).

229 See e.g. Jill Cetina, Mark Paddrik, Sriram Rajan Stressed to the Core: Counterparty Concentrations and Systemic Losses in CDS Markets OFR Working Paper 16-01 (2016) (using transactional credit default swaps data to reconstruct (part of) the financial network).

${ }^{230}$ Sebastian Poledna et al., The Multi-Layer Network Nature of Systemic Risk and Its Implications for the Costs of Financial Crises, 20 J. FIN. STABILITY 70, 77 (2015): (showing that the "marginal contributions from individual liabilities [to systemic risk] depend not only on the two parties involved but also on the conditions of all nodes in the network"); Cont et al., supra note 209, at 32 (finding that the resilience of an institution's counterparties matters: an institution with relatively weak counterparties may be more contagious than an institution with a similar number of more resilient counterparties that are better able to manage potential losses).

${ }^{231}$ Dimitrios Bisias et al., A Survey of Systemic Risk Analytics, 4 ANN. REV. Fin. ECON. 255, 263 (2012):

Participants who had purchased credit default swap (CDS) protection from AIG Financial Products (AIGFP) were unknowingly exposed to wrong-way risk because they could not see the full extent of AIG's guarantee exposures to others, and Lehman Brothers disguised the full extent of its leverage from other participants via its Repo 105 transactions. 
network, not only within but also across jurisdictions, financial institutions cannot make fully rational lending decisions. ${ }^{232}$

At the same time, however, both extensive reporting and disclosure obligations can create problems. On the one hand, gathering and reporting massive amounts of information is costly for a SIFI, and so is processing it for the regulator. On the other hand, some degree of opacity is required to ensure that trading firms can make profits and can derive benefits from investing in information. ${ }^{233}$ Moreover more stringent reporting obligations raise issues of confidentiality.

How to strike the right balance between the benefits and costs of reporting and disclosure obligations is therefore a complex problem; what is certain is that such a balance is altered by the development of network theory and its use in policymaking. As Yellen concluded, "while market integrity and appropriate confidentiality are important considerations, the events of the financial crisis have clearly shown that effective systemic risk management demands more, and not less, data disclosure." 234 The questions that researchers should ask are: how much more data disclosure is required? Which data should only be reported to the regulator and which should be disclosed?

\section{CONCLUSION}

This article advocates the use of insights from network theory to improve on regulations aiming to curb systemic risk, which arises because financial institutions are interconnected with each other in a complex web. In the last ten years, policymakers have indeed started making financial regulation network-sensitive in key areas such as capital ratios, SIFI designations, and merger controls. Yet, despite the increased attention to corporate governance as an area of intervention for financial regulation both from policymakers and especially from legal scholars, no one had yet suggested that network theory tools could be usefully applied to the governance domain as well. This article argues that they should be for one simple reason: any deviation from corporate governance and corporate law core principles and rules with a view to curbing systemic risk is justified to the extent that the actions of the relevant players, that is, the managers, directors and shareholders of any given SIFI, affect systemic risk. Any rule that does account for a given institution's level of riskiness for the system as a whole is bound to err on the side of caution for some SIFIs and be insufficient for others. Network theory provides sophisticated and reliable tools to measure individual SIFIs' contribution to

${ }^{232}$ Thurner \& Poledna, supra note 71, at 1 (noting that the lack of transparency "makes it impossible for individual banks to make rational decisions on lending terms in a financial network, which leads to a fundamental principle: opacity in financial networks rules out the possibility of rational risk assessment").

${ }^{233}$ Bisias et al., supra note 231, at 263.

${ }^{234}$ Yellen, supra note 4. 
systemic risk, which can thus be used to adjust the operation of the individual corporate governance requirements for each SIFI.

In particular, we show how network theory can be used to improve four prescriptions of this kind. First, we discuss the proposal by Armour and Gordon to expand the liability of managers and directors of SIFIs as a stick to deter excessive risk-taking on their part. We show that adding a network component to their proposed regime would determine the amount of liability for SIFI managers and directors as a function of the SIFI's effective systemic relevance. With a one-sizefits all liability regime for managers and directors, they would have an incentive to become as systemically important as possible in order to maximize the chances of a bail-out ex post and thus to minimize financing costs ex ante. A network-sensitive liability regime would avoid this drawback.

Similarly, the proposal by Bebchuk and Spamann of including a broader basket of securities - i.e. preferred stocks and bonds - in the compensation of banks' managers and the European Union's cap on bank executives variable compensation impose exactly the same constraints on all banks. Yet, setting compensation in a way that prevents alignment of incentives between managers and shareholders is justified to the extent that their behavior can affect the financial system's stability. Last, we turn to the proposal advocated by Listokin and Mun that a failing target SIFI's shareholders voting rights in merger resolutions should be replaced by attenuated appraisal rights. We show that, once again, their proposal does not account for the position occupied in the network by the target firm. And because Listokin and Mun's solution may have a negative impact on shareholder monitoring and investors' willingness to recapitalize the bank before it has to be rescued via a merger with a sounder institution, a network-sensitive tweak would improve on a one-size-fits-all solution.

In short, while remaining agnostic on the specific advantages and disadvantages of the policies discussed, we argue that, without a network-sensitive component, corporate governance regulations do not speak the same language as the problem they intend to solve, namely, systemic risk, and therefore cannot achieve their intended goal of curbing it. In developing corporate governance reforms aimed at preserving financial stability, legal scholars should use the intuitions and tools provided by network theory to finesse their proposals and more effectively tackle systemic risk. 


\section{about ECGI}

The European Corporate Governance Institute has been established to improve corporate governance through fostering independent scientific research and related activities.

The ECGI will produce and disseminate high quality research while remaining close to the concerns and interests of corporate, financial and public policy makers. It will draw on the expertise of scholars from numerous countries and bring together a critical mass of expertise and interest to bear on this important subject.

The views expressed in this working paper are those of the authors, not those of the ECGI or its members. 


\section{ECGI Working Paper Series in Law}

\section{Editorial Board}

Editor

Consulting Editors

Editorial Assistants
Amir Licht, Professor of Law, Radzyner Law School, Interdisciplinary Center Herzliya

John Coates, John F. Cogan, Jr. Professor of Law and Economics, Harvard Law School

Horst Eidenmüller, Freshfields Professor of Commercial Law, University of Oxford

Curtis Milhaupt, Professor of Law, Stanford Law School

Niamh Moloney, Professor of Law, Department of Law, London School of Economics and Political Science

Tamas Barko , University of Mannheim

Vanessa Wang, University of Mannheim 


\section{Electronic Access to the Working Paper Series}

The full set of ECGI working papers can be accessed through the Institute's Web-site (www.ecgi.global/content/working-papers) or SSRN:

Finance Paper Series http://www.ssrn.com/link/ECGI-Fin.html

Law Paper Series http://www.ssrn.com/link/ECGI-Law.html 